Check for updates

Cite this: Chem. Soc. Rev., 2020, 49, 7331

Received 28th May 2020

DOI: $10.1039 / \mathrm{d} 0 \operatorname{cs} 00617 \mathrm{c}$

rsc.li/chem-soc-rev

\section{Fundamental studies of functional nucleic acids: aptamers, riboswitches, ribozymes and DNAzymes}

\begin{abstract}
Ronald Micura (D) *a and Claudia Höbartner (D)*b
This review aims at juxtaposing common versus distinct structural and functional strategies that are applied by aptamers, riboswitches, and ribozymes/DNAzymes. Focusing on recently discovered systems, we begin our analysis with small-molecule binding aptamers, with emphasis on in vitro-selected fluorogenic RNA aptamers and their different modes of ligand binding and fluorescence activation. Fundamental insights are much needed to advance RNA imaging probes for detection of exo- and endogenous RNA and for RNA process tracking. Secondly, we discuss the latest gene expression-regulating mRNA riboswitches that respond to the alarmone ppGpp, to PRPP, to $\mathrm{NAD}^{+}$, to adenosine and cytidine diphosphates, and to precursors of thiamine biosynthesis (HMP-PP), and we outline new subclasses of SAM and tetrahydrofolate-binding RNA regulators. Many riboswitches bind protein enzyme cofactors that, in principle, can catalyse a chemical reaction. For RNA, however, only one system ( $g(m S$ ribozyme) has been identified in Nature thus far that utilizes a small molecule - glucosamine-6-phosphate - to participate directly in reaction catalysis (phosphodiester cleavage). We wonder why that is the case and what is to be done to reveal such likely existing cellular activities that could be more diverse than currently imagined. Thirdly, this brings us to the four latest small nucleolytic ribozymes termed twister, twister-sister, pistol, and hatchet as well as to in vitro selected DNA and RNA enzymes that promote new chemistry, mainly by exploiting their ability for RNA labelling and nucleoside modification recognition. Enormous progress in understanding the strategies of nucleic acids catalysts has been made by providing thorough structural fundaments (e.g. first structure of a DNAzyme, structures of ribozyme transition state mimics) in combination with functional assays and atomic mutagenesis.
\end{abstract}

${ }^{a}$ Institute of Organic Chemistry and Center for Molecular Biosciences Innsbruck CMBI, Leopold-Franzens University Innsbruck, Innsbruck, Austria.

E-mail: ronald.micura@uibk.ac.at

${ }^{b}$ Institute of Organic Chemistry and Center for Nanosystems Chemistry CNC, Julius-Maximilians University Würzburg, Würzburg, Germany.

E-mail: claudia.hoebartner@uni-wuerzburg.de

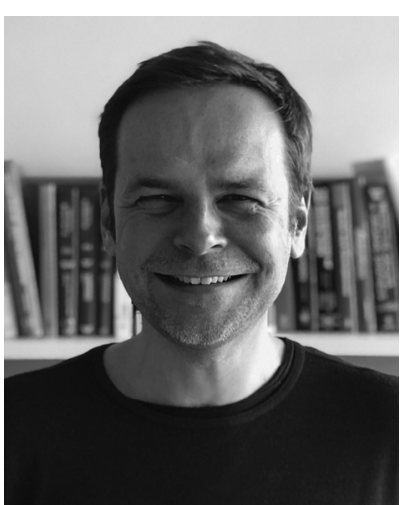

Ronald Micura
Ronald Micura studied chemistry at the University of Linz. He received his $P h D$ in the field of phycobilin pigments under the supervision of Karl Grubmayr in 1995. Immediately thereafter he joined the laboratory of Albert Eschenmoser at ETH Zürich, and then moved to The Scripps Research Institute, to perform postdoctoral research on alternative nucleic acids. He started independent research funded by an APART-fellowship (Austrian Academy of Science) at the University of Linz. In 2004, he was appointed Professor of Organic Chemistry at the University of Innsbruck. His research focuses on the chemistry, chemical biology, and biophysics of RNA.

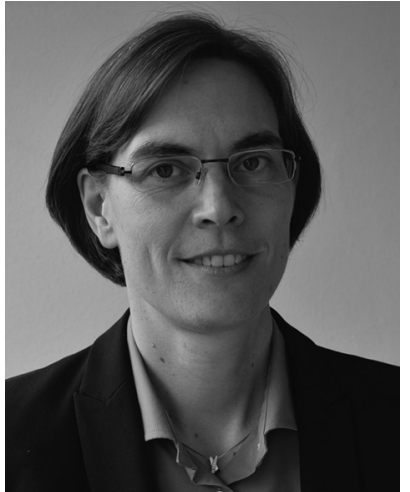

Claudia Höbartner
Claudia Höbartner studied at TU Wien and ETH Zürich, and received her $P h D$ under the supervision of Ronald Micura at the University of Innsbruck in 2004. After postdoctoral work with Scott Silverman at the University of Illinois at Urbana Champaign, she joined the Max Planck Institute for Biophysical Chemistry in Göttingen as a research group leader. In 2014 she was appointed at the University of Göttingen, and since 2017 she holds a Chair of Organic Chemistry at the University of Würzburg. Her main research interests concern the chemistry and chemical biology of functional nucleic acids and RNA modifications. 


\section{Introduction}

Nature has endowed nucleic acids, both DNA and RNA, with fascinating properties that allow them to fold into complex three-dimensional structures forming the basis for their functional diversity and reactivity. ${ }^{1-3}$ RNA and DNA cannot only mould pockets to recognize small molecules with high specificity and selectivity, ${ }^{4}$ they also possess the inherent propensity for structural ambiguities and alterations in shape which are frequently applied as the molecular basis for distinct signalling pathways in the cell. ${ }^{5,6}$ Additionally, nucleic acids are dynamic in structure on timescales that vary from milliseconds to minutes and even hours which is crucial for ligand recognition and discrimination on the one hand (fast events), ${ }^{7-9}$ and on the other hand, for folding/refolding of alternative secondary structures (slower events), such as terminator/antiterminator stem formation to regulate gene expression. ${ }^{10}$ On top, these structural and dynamic properties are key to triggering reactivity, culminating in the occurrence of nucleic acids catalysts. ${ }^{11,12}$

With regard to structural diversity and reactivity, RNA is often deemed the more powerful sibling of DNA. This impression originates from the many naturally occurring representatives in form of non-coding RNAs with important cellular functions (e.g. riboswitches). ${ }^{4}$ Nevertheless, many functional nucleic acids, RNA and DNA, have been generated artificially in the test tube and are not limited to the functions found in Nature. The activities of ligand binding (sensors) and catalysis (ribozymes, DNAzymes) have been combined in aptazymes, ${ }^{13,14}$ although the currently known combinations are mostly limited to triggering "simple" reactions, namely phosphodiester cleavage or ligation. Only few artificial nucleic acids have been identified, which employ small molecules such as nicotinamide adenine dinucleotide $\left(\mathrm{NAD}^{+} / \mathrm{NADH}\right)$ or thiamine as cofactors. However, these ribozymes use synthetic substrates that were fine-tuned for the in vitro selection process. ${ }^{15,16}$ Thus far, nucleic acids that are able to conduct reactions equivalent to modern cellular transformations, for instance, selective methylation in trans, using cofactors such as cobalamine or $S$-adenosyl methionine (SAM), ${ }^{17}$ or any other natural methyl group donor, have not yet been identified. Finding such reactivity would have a major impact on the (protein-free) RNA world hypothesis and prebiotic chemistry. ${ }^{18,19}$

In the laboratory, functional nucleic acids are identified by in vitro selection (also known as SELEX) starting from random RNA libraries. The concept was introduced by the Szostak ${ }^{20}$ and Gold $^{21}$ research groups about 30 years ago, and consists of repeated cycles of selection and amplification for the enrichment of RNA sequences with desired functions. The functions range from specific non-covalent interactions with small and large molecules to catalysing various chemical reactions of diverse substrates. Although there are numerous successful examples known today, and the procedures are constantly refined and expanded by modern technologies, ${ }^{22-24}$ the outcome of in vitro selection (also known as SELEX) is still highly unpredictable. Moreover, it is currently impossible to design functional nucleic acids from first principles. Fundamental

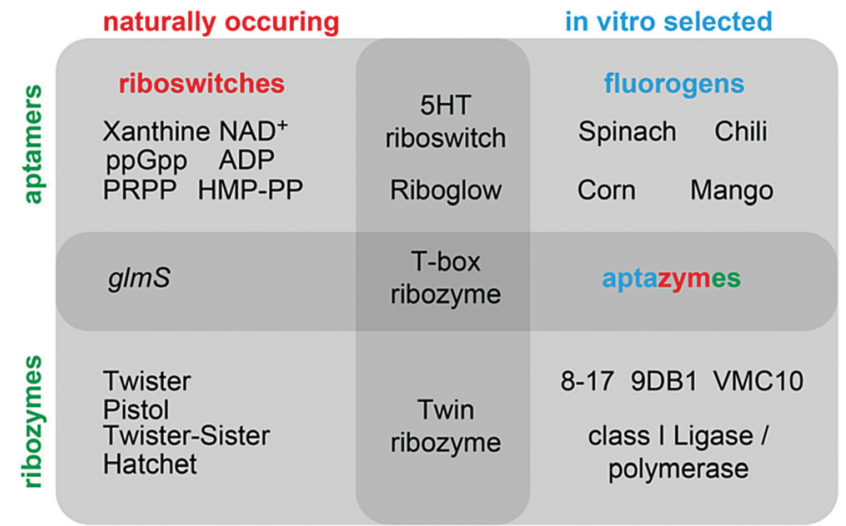

Fig. 1 Overview of classes of functional nucleic acids (with selected examples) covered in this review and their interconnections.

biochemical and biophysical studies of the NAs provide much needed data on the thermodynamic and kinetic levels. High throughput methods reveal insights into folding and activity landscapes at an impressive pace. ${ }^{25,26}$ Combined with machine learning approaches, these methods may form the basis for new algorithms to generate aptamer and ribozyme candidates in silico, and to derive guidelines for the evolution of high selectivity, high rate acceleration and multiple turnover. In the protein world, important steps in this direction have been successfully demonstrated, with the de novo design of protein folds, enzymes, logic gates and molecular switches. ${ }^{27-30}$ Similar exciting advances are to be expected in the field of nucleic acids research. ${ }^{31,32}$

This review summarizes recent developments in the fields of in vitro selected fluorogenic RNA aptamers and riboswitch discovery, and discusses more intensively the structures and mechanistic elucidations of recently discovered natural ribozymes, which we contrast with in vitro selected DNAzymes catalysing phosphodiester cleavage and ligation chemistry (Fig. 1).

\section{Fluorogen-activating RNA aptamers}

Organic chromophores have been early targets for the in vitro selection of RNA aptamers. ${ }^{20,33}$ The successful discrimination of closely related structural analogues of anthraquinone dyes was demonstrated by large differences in binding affinity. The Reactive Blue A and sulforhodamine-binding aptamers constituted early examples of specific recognition of anionic ligands despite the polyanionic nature of RNA. About 10 years later, based on the crystal structure of the Malachite green aptamer, ${ }^{34}$ it was recognized that ligand binding resulted in restricted conformational freedom of the ligand and this observation culminated in the discovery of strong fluorescence enhancement by the malachite green and sulforhodaminebinding aptamers. ${ }^{35}$

In the last decade, fluorescence turn-on aptamers have been an emerging class of synthetic functional nucleic acids for RNA tracking and visualization in cellular and molecular biology. Also termed fluorescent light-up probes, or fluorogen-activating aptamers (FLAPs), an increasing number of in vitro evolved 
30 to 100 nt long RNAs are now known to activate the fluorescence of various classes of conditional fluorophores. Most of the recent examples and their applications have been summarized in excellent reviews. ${ }^{3,36-39}$ Here, we focus on different mechanisms and structural principles of fluorescence activation and discuss open challenges to be addressed by fundamental biophysical studies in combination with further evolution and engineering.

\section{HBI-binding aptamers - Spinach, Broccoli, Corn, Chili}

The first aptamer in the family of "RNA mimics of green fluorescent protein (GFP)" was named spinach. ${ }^{40}$ It was selected to bind the difluorinated analogue of the GFP chromophore, named DFHBI (Fig. 2A). The Spinach RNA binds the deprotonated ligand, and the emission wavelength and quantum yield resemble enhanced GFP. Broccoli is a second generation aptamer that was selected with a modified DFHBI analogue, DFHBI-1T, and was optimized to function in cellular conditions at low $\mathrm{Mg}^{2+}$ concentration. ${ }^{41}$ Spinach and Broccoli RNAs share similar primary and secondary structures, and use the same structure-based mechanism of fluorescence activation that relies on reducing non-radiative deactivation of the excited state. The ligand binding site involves a guanine quadruplex of complex topology. ${ }^{42,43}$ The ligand stacks on top of one G-quartet, and, in spinach, it is sandwiched between the G-quartet and a basetriple (Fig. 2B). The extended $\pi$-stacking interactions reduce the conformational flexibility of the ligand, resulting in rigidification and reduced conformational flexibility, thus promoting fluorescence emission. Although the 3D structure of Broccoli has not

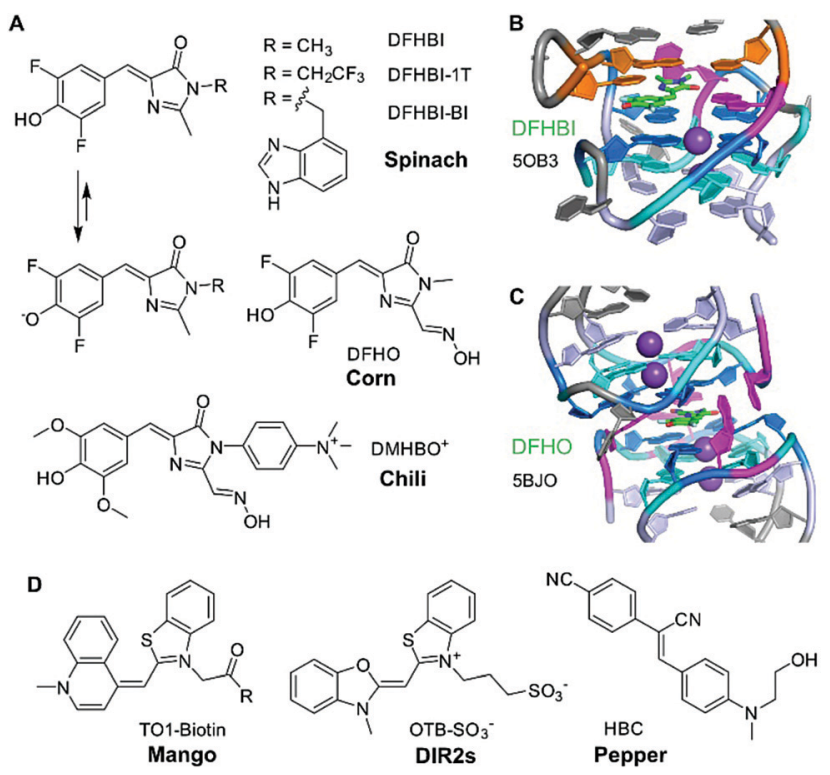

Fig. 2 Fluorogen-activating RNA aptamers. (A) HBI ligands of Spinach, Broccoli, Corn and Chili. (B) Core of iSpinach with DFHBI sandwiched between G-quartet (blue, cyan) and UAU base triple (orange), held in place by $\mathrm{H}$-bonding with guanine and methyl $\pi$ interaction with adenine (magenta). (C) Dimeric quadruplex of Corn with $\mathrm{H}$-bonding contacts to the oxime side chain and phenolate oxygen. (D) Ligand structures for Mango, DIR2s, and Pepper aptamers. been explicitly solved, it is reported to be highly related to Spinach, and single point mutations are known to tune fluorescence emission wavelengths and intensities, as well as RNA folding kinetics. ${ }^{44-46}$ In vitro evolution of Spinach based on microfluidic screening of water-in-oil droplets resulted in a variant named iSpinach, ${ }^{47}$ with reduced salt-sensitivity, higher thermal stability and increased brightness, despite containing an almost identical core structure of the quadruplex in the ligand binding site. ${ }^{48}$

Another quadruplex-containing aptamer named corn was obtained in an in vitro selection experiment with an extended derivative of DFHBI that carries an oxime sidechain, named DFHO. ${ }^{49}$ Corn differs from Spinach and Broccoli not only in the redshifted emission wavelength and enhanced photostability, but also in the architecture of the ligand binding site. ${ }^{50}$ Spinach and Broccoli are monomeric aptamers, while Corn forms a dimer, and the ligand is bound at the interface of the two interacting RNA molecules (Fig. 2C). ${ }^{50}$ Interestingly, the quadruplex dimer is also formed in the apo state (i.e., in the absence of the ligand), with a collapsed, symmetric conformation. ${ }^{51}$ Moreover, structures of Corn in complex with the quadruplexbinders thioflavin $\mathrm{T}$ (ThT) and thiazol orange (TO) helped to rationalize their strong fluorescence activation by binding to the Corn quadruplex dimer. ${ }^{51}$

Spinach, Broccoli and Corn bind fluorinated HBI analogues with low $\mathrm{p} K_{\mathrm{a}}$ values that are easily deprotonated and exist predominantly as phenolates under physiological conditions. In contrast, the Chili aptamer, ${ }^{52}$ which is derived from the earlier reported 13-2 aptamer, ${ }^{40}$ binds and activates the dimethoxy-substituted analogue DMHBI exclusively in the protonated state. The phenolic proton is lost upon excitation of the bound ligand, resulting in fluorescence emission from the phenolate form. The excited state proton transfer (ESPT) leads to the large Stokes shifts of $>130 \mathrm{~nm}$ observed in Chili. Moreover, Chili is able to activate the emission of several ligands with different substitution patterns, resulting in fluorescence emission in the green, yellow and red wavelength range. ${ }^{53}$ The introduction of a permanent positive charge in the ligand sidechain in $\mathrm{DMHBI}^{+}$and $\mathrm{DMHBO}^{+}$led to strongly enhanced affinities, and maintained high selectivity for the Chili aptamer. The structure of any Chili RNA-ligand complex has not yet been reported. However, the high guanine content ( $48 \% \mathrm{G})$, and preliminary NMR spectra suggest the presence of a quadruplex core structure. ${ }^{42,53}$ Initial hints into the organization of the aptamer and the relative location of the ligand were obtained by supramolecular FRET. ${ }^{54}$ The fluorescent nucleobase analogue 4-cyanoindol was covalently incorporated into the RNA aptamer and served as donor for energy transfer to the non-covalently bound $\mathrm{DMHBI}^{+} / \mathrm{DMHBO}^{+}$ligands that served as acceptor. ${ }^{54}$ Additional fundamental studies of ESPT photophysics in combination with structural studies may reveal the identity and function of the proton acceptor. Preliminary data regarding the involvement of a crucial nucleobase nitrogen have been obtained by mutagenesis experiments, but more detailed investigations are needed to surface the mechanism of how Chili mimics the large Stokes shift (LSS) fluorescent proteins, such as LSSmOrange and LSSmKate. ${ }^{55}$ 


\section{TO-binding aptamers - Mango}

The second heavily investigated and structurally well-characterised class of fluorogenic aptamers is the Mango family, which binds to derivatives of thiazole orange (TO). Originally selected to bind biotinylated TO1 with a PEG linker, ${ }^{56}$ four generations of the Mango aptamer were evolved by advanced methods, including fluorescence-activated droplet sorting. ${ }^{47,57,58}$ The structures of Mango variants from generations I-IV are known, and have recently been discussed in detail. ${ }^{3,58-61}$ The core of all Mango aptamers contains a G-quadruplex, primarily responsible for stacking and rigidification of the bound ligand. While the first generation included the PEG linker and the biotin in packing onto the G-quartet next to $\mathrm{TO} 1,{ }^{61}$ later generations exhibited improved fluorophore planarity resulting in higher brightness. Mango-III and iMango-III exhibited additional sophisticated structural elements, such as an unusual pseudoknot structure containing non-canonical trans base pairs in parallel strand orientation. $^{58,62}$

\section{Additional recent light-up aptamers}

Besides HBI- and TO-binding aptamers described above, several other aptamers have recently been reported to enhance the brightness of conditional fluorophores. These include the DIR2s aptamer that binds asymmetric cyanine dyes such as dimethylindole red (DIR) and oxazole thiazole blue (OTB). ${ }^{63}$ Interestingly, this aptamer does not form a G-quadruplex core for planarization of the fluorophore, but instead uses a mixedsequence tetrad to promote rigidification, supported by a single adenine stacking on top of the thiazole ring. ${ }^{64}$

The most recent "spicy" addition to the family of fluorogenic vegetable and fruit aptamers for RNA imaging is the Pepper aptamer. ${ }^{65}$ The small ca. 45 nt long RNA binds and activates a family of eight related synthetic dyes, derived from substituted aminobenzylidene cyanophenyl acetonitriles (HBC, Fig. 2D) that exhibit a structurally rigid electron acceptor and a strong electron donor to produce emission colours in the range from cyan to red. Structural analysis of the predicted bulged stem-loop core will likely reveal the molecular basis of this colourful diversity. To avoid confusion, it should be noted that a second strategy for RNA tracking was recently introduced under the name Pepper RNA, which follows a very different mechanism based on RNA-mediated stability of a fluorescent protein. ${ }^{66}$

A different fluorogenic mechanism is employed by the recently reported silicon rhodamine-binding RNA aptamer (SiRA). ${ }^{67}$ Specific binding of silicon rhodamine to the RNA shifts the equilibrium between the closed non-colored spirolactone and the open fluorescent zwitterion, resulting in turn-on of NIR fluorescence emission.

Besides fluorophore rigidification, another common mechanism of fluorescence enhancement is the RNA-based disruption of chromophore-quencher conjugates. In this case, binding of RNA aptamers either to the fluorophore or to the quencher results in enhanced emission. Early examples include non-emissive fluorescein derivatives with 4-methoxyphenyl-piperazinyl side chains that served as donors by photoinduced electron transfer (PET). ${ }^{6}$ Aptamers have been evolved for selective binding of black-hole-quenchers to eliminate contact-mediated quenching of fluorescence. ${ }^{69,70}$ Other rationally designed fluoromodules used rhodamine dyes with appended dimethylaniline or dinitroaniline quenchers. ${ }^{71}$ The SRB-2 aptamer, termed rainbow, then allowed for dual colour fluorogenic RNA imaging with low background in live cells. ${ }^{72,73}$ Another recently introduced concept takes advantage of self-quenching upon fluorophore dimerization. A cellpermeable fluorogenic dimer of sulforhodamine B (Gemini-561) was used for the in vitro selection and resulted in the dimeric o-Coral aptamer with enhanced performance for RNA imaging. ${ }^{74}$

The first example of a natural aptamer that was repurposed for the development of a fluorogenic RNA imaging platform was the cobalamin riboswitch. ${ }^{75}$ Cobalamin served as fluorescence quencher when appended to different fluorescent dyes, and binding to the RNA elicited fluorescence enhancement due to reduction of contact quenching. This strategy holds promise for engineering of differently coloured fluoromodules with high affinity. However, the relatively high background of the Riboglow platform is an inherent difficulty encountered in systems that rely on contact quenching in solution.

\section{Riboswitch RNAs}

Riboswitches are utilized by bacteria to sense metabolites and ions in order to regulate gene expression. To date, riboswitches that respond to nearly fourty distinct small ligands have been discovered and experimentally validated. ${ }^{76,77}$ For most of them, $\mathrm{X}$-ray crystallography has revealed the three-dimensional structures of their ligand-binding aptamer domains, shedding light on the enormous diversity of RNA folds and RNA recognition patterns. ${ }^{78-80}$ The first riboswitch validation reports date back to $2002^{81-84}$ and covered riboswitches that are very common and are present in bacteria from nearly all lineages. They respond to thiamine pyrophosphate, cobalamine, adenine, guanine, $S$-adenosylmethionine, glycine, lysine, cyclic diguanylate, and many more. Other riboswitches are exceedingly rare and appear in only a few species. Nearly all of the currently known riboswitches have been identified by a single laboratory (Ronald R. Breaker). They predict that there are potentially many thousands of distinct bacterial riboswitches remaining to be discovered. ${ }^{76}$ Recent articles on riboswitch diversity and distribution cover biocomputational aspects, ${ }^{76,77}$ several reviews summarize their structural concepts, ${ }^{78-80}$ and some focus on latest developments to use riboswitches as sensor tools in biotechnological and biomedical applications. ${ }^{10,14,85-90}$

Here, we concisely focus on the most recent additions to riboswitches (Fig. 3) and on a few reports that aim at utilizing riboswitch scaffolds to engineer ligand specificities and chemical reactivity towards systems that function as riboswitch-ribozymes.

\section{Recent additions to natural riboswitch systems}

Xanthine riboswitch. The most recent discovery of a bacterial riboswitch class that has been assigned to a novel ligand is the xanthine riboswitch. ${ }^{91}$ Its consensus sequence forms a hairpin 

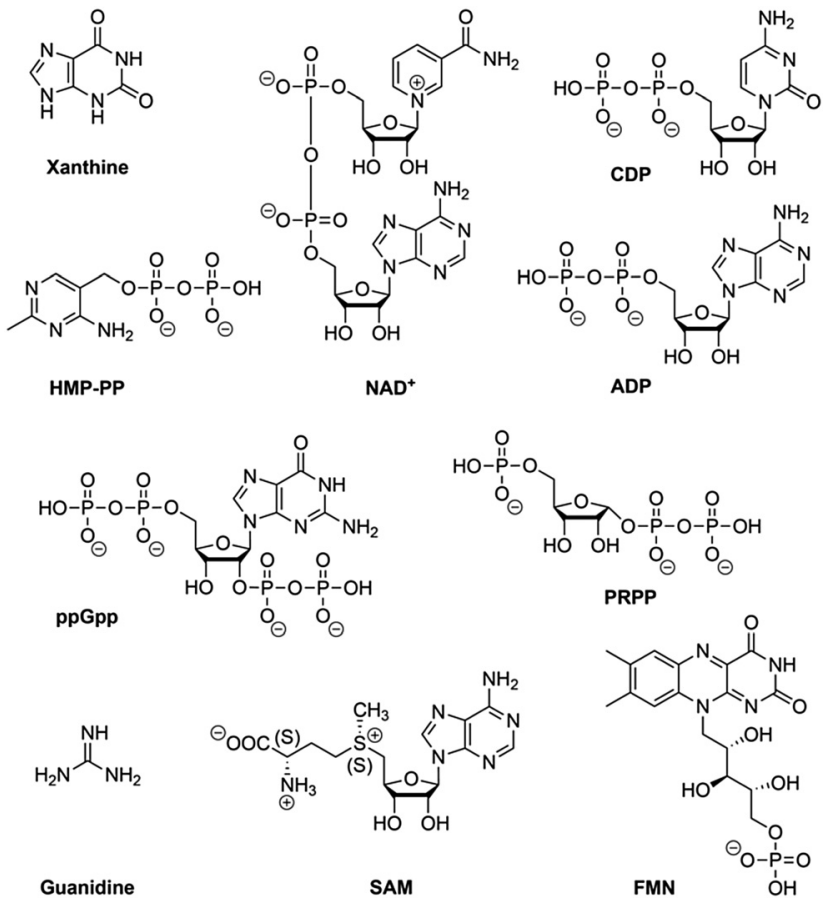

Guanidine

SAM

ÖH

Fig. 3 Ligands of recently discovered bacterial $m R N A$ riboswitch classes.

structure with an internal bulge that includes numerous highly conserved nucleotides and was originally annotated as an orphan riboswitch candidate with NMT1 motif. Members of the xanthine riboswitch class regulate genes predominantly related to purine transport and oxidation, thus avoiding the effects of overproduction of these common purine metabolites (Fig. 3).

$\mathrm{NAD}^{+}$riboswitch. The nadA riboswitch is present in various Acidobacteria species with more than hundred representatives identified upstream of nadA genes. ${ }^{92}$ These code for an enzyme in the biosynthetic pathway of the ubiquitous coenzyme nicotinamide adenine dinucleotide $\left(\mathrm{NAD}^{+}\right)$. The consensus secondary structure fold of this RNA implies two structurally related ligand-binding aptamers which control translation initiation. Biochemical analyses suggested that the first domain selectively binds ligands containing an adenosine 5 -diphosphate (ADP) moiety. A recent crystal structure of the first aptamer domain shows an open binding site for selective recognition of the adenine base, and $\mathrm{Mg}^{2+}$-mediated interaction with the pyrophosphate moiety. ${ }^{93}$ Interestingly, the nicotinamide portion of $\mathrm{NAD}^{+}$is solvent-exposed. Binding of $\mathrm{NAD}^{+}$to the second putative aptamer appears very weak in vitro despite sequence and structural similarities between the tandem domains. Further structural work on the second domain and the full tandem aptamer is required to understand the mode of recognition and its precise function.

In this context, we stress that the $\mathrm{NAD}^{+}$aptamer discriminates $\mathrm{NAD}^{+}$over NADH by a factor of about two, while $\mathrm{NADP}^{+}$is not binding to this RNA. The assignment to $\mathrm{NAD}^{+}$as cognate ligand was based on the higher cellular concentration of $\mathrm{NAD}^{+}$ $(\sim 2.6 \mathrm{mM})$ compared to $\mathrm{NADH}(\sim 120 \mu \mathrm{M})$ in bacteria. $^{92}$ Furthermore, it cannot be excluded that a riboswitch exists for NADP as well, however, such an RNA motif is likely distinct from the $\mathrm{NAD}^{+}$motif because the $2^{\prime}-\mathrm{OH}$ is tightly recognized in the pocket by $\mathrm{H}$-bonding ${ }^{93}$ and a $2^{\prime}-\mathrm{OPO}_{3}{ }^{2-}$ group (as present in $\mathrm{NADP}^{+}$) would cause steric interference.

4-Amino-5-hydroxymethyl-2-methylpyrimidine diphosphate (HMP-PP) riboswitch. The thiS motif was identified as a riboswitch candidate frequently associated to genes involved in the vitamin B1 synthesis pathway. The This protein is responsible for delivering sulfur to form the thiazole moiety of the thiamine precursor 5-(2-hydroxyethyl)-4-methylthiazole phosphate (HET-P). Biochemical and genetic data demonstrated that thiS RNAs function as sensors of the required second thiamine precursor HMP-PP to turn on HET-P production. HMP-PP and HET-P are then fused to ultimately form the final active coenzyme thiamine pyrophosphate (TPP). ${ }^{94}$ The small ligand-sensing aptamer domain of the HMP-PP riboswitch ( $c a .30 \mathrm{nt}$ ) is almost entirely embedded in a transcription terminator stem. Such a situation has not been observed before in other transcriptionally controlled riboswitches, which require individual aptamer domains with a competing secondary structure element that adjoins (and partially overlaps with) the terminator sequence.

Guanidine riboswitches ( $\boldsymbol{y} \boldsymbol{k} \boldsymbol{k} \boldsymbol{C}$ RNA subtype 1). Comparative genomics also led to the prediction of the $y k k C$ RNA motif as a riboswitch candidate. It resisted initial efforts at experimental verification and remained orphan for a very long time. ${ }^{95}$ Today, it is known that the $y k k C$ motif includes at least five distinct bacterial riboswitch classes. The $y k k C$ subtype 1 RNAs are guanidine-I riboswitches that regulate the expression of guanidinespecific carboxylase and transporter proteins. ${ }^{96-102}$

Guanosine tetraphosphate (ppGpp) riboswitch (ykkC RNA subtype 2a). The remaining $y k k C$ RNAs have been categorized into four major groups termed subtypes 2a-2d. Subtype 2a RNAs are riboswitches that respond to the bacterial alarmone ppGpp and they typically control genes for amino acid biosynthesis. ${ }^{103}$

Phosphoribosyl pyrophosphate (PRPP) riboswitch (ykkC RNA subtype 2 b). This riboswitch senses the purine biosynthetic intermediate PRPP and frequently partners with guanine riboswitches to regulate purine biosynthesis genes. ${ }^{95}$ How $y k k C$ riboswitches discriminate ppGpp from PRPP ligands was disclosed in recent crystallographic structural studies. ${ }^{104,105}$ Subtype 2b RNAs employ an add-on helix to adjust specificity for the polyanionic ligands. ${ }^{105}$

Adenosine and cytidine $5^{\prime}$-diphosphate riboswitches $(y k k C$ RNA subtype 2c). These RNA motifs are located upstream of genes encoding hydrolase enzymes that cleave the phosphoanhydride linkages of nucleotide substrates. Representatives of subtype $2 \mathrm{c}$ mostly sense adenosine and cytidine $5^{\prime}$-diphosphates (ADP, dADP, CDP, and dCDP), while the corresponding nucleoside $5^{\prime}$-triphosphates are not responding. ${ }^{106}$ High ligand concentrations in vivo are predicted to turn on the production of hydrolase enzymes, which may function to balance the concentrations of cellular nucleotides, but elucidation of the switching mechanism requires further investigation. Fundamental structural studies and their comparison to in vitro selected, 5'-triphosphate-binding ATP/GTP aptamers ${ }^{107,108}$ are needed and expected to uncover similarities or differences 
in evolution of ligand discrimination in Nature and in the laboratory.

SAM riboswitches. Although SAM riboswitches belong to the group of riboswitches that were discovered first, ${ }^{109,110}$ a new subclass has been identified recently. ${ }^{111}$ The SAM-VI riboswitch adopts a new fold that recognizes its ligand in a distinct manner compared to the previously known five SAM riboswitch classes. $^{112}$

Tetrahydrofolate riboswitches. The folE motif RNAs selectively interact with the ubiquitous cofactor tetrahydrofolate (THF) and are commonly found in Gram-negative bacteria. ${ }^{113}$ Biochemical validation of these aptamers demonstrated that they are distinct from aptamers of the previously validated THF riboswitch class found in Gram-positive bacteria. ${ }^{114}$ They define a second THF riboswitch class, named THF-II.

\section{Riboswitch goes ribozyme - and an outlook on non-protein RNA methyltransferases}

Many riboswitches bind protein enzyme cofactors that can catalyse or mediate chemical reactions. ${ }^{115,116}$ Thus far, however, only one RNA system ( $g \operatorname{lm} S$ riboswitch-ribozyme) has been identified in nature that utilizes a small molecule - namely glucosamine-6-phosphate - to participate directly in reaction catalysis (phosphodiester cleavage). ${ }^{117}$ We wonder why not more such examples have been found and what we have to undertake to disclose these likely existing cellular activities that could be more widespread than currently imagined. Moreover, in the hypothetical RNA world, ${ }^{118-122}$ ribozymes with the capability to conduct more diverse reactions in a primitive cell might have taken the role of today's protein enzymes. Such ribozymes could have evolved from riboswitches, thereby utilizing the aptamer binding pockets for proper positioning of substrates and cofactors. A recent study delineates such a pathway for the evolution of an aminoacylation ribozyme which could be part of a primitive translation system. ${ }^{123}$

An aminoacylation ribozyme evolved from a natural tRNAsensing T-box riboswitch. The naturally occurring T-box riboswitches selectively sense the aminoacylation status of cognate tRNAs. ${ }^{124}$ Suga and coworkers introduced a random sequence domain into a T-box-tRNA conjugate and selected ribozymes that aminoacylated their own the 3 '-terminal hydroxy groups. ${ }^{123}$ One of these ribozymes recognizes the anticodon and D-loop of tRNA comparably to the parental T-box. It charges biotinylated phenylalanine onto the $3^{\prime}$ end of the cognate tRNA in trans with very high selectivity. The authors further showed the ribosomal synthesis of a biotinylated peptide in a ribozyme-coupled in vitro translation system, in which the ribozyme catalysed specific tRNA aminoacylation in situ.

Riboswitch motifs as scaffolds for genetically encodable small-molecule biosensors. The advantage of utilizing natural scaffolds for aptamer selections has been convincingly demonstrated by a recent study: Although aptamers can be created de novo against almost any desired target through in vitro selection, most of them are not easily integrated into tools for molecular or synthetic biology. To overcome this bottleneck, Batey and coworkers developed an approach using secondary- and tertiary-structural scaffolds derived from purine and cyclic di-GMP riboswitches, and the hammerhead ribozyme. ${ }^{125}$ When applied to precursor molecules (namely, 5-hydroxytryptophan and 3,4-dihydroxyphenylalanine) of the neurotransmitters serotonin and dopamine, this approach yielded easily identifiable and characterisable aptamers. The sensor domains were coupled to readout domains and allowed engineering of powerful nucleic acid-sensory devices for in vitro and cellular applications.

Building selection strategies on natural riboswitch scaffolds could also impact the field of 'aptazymes', 14,126,127 namely the development of allosteric RNA devices that currently predominantly rely on de novo selected small molecule aptamers (e.g. theophylline, tetracycline, etc.) with adjoining self-cleaving small ribozymes of natural origin (hammerhead, HDV, twister, pistol, etc.). ${ }^{128-130}$ Such allosteric RNA devices are increasingly being regarded as effective tools for monitoring enzyme evolution, optimizing engineered metabolic pathways, modulating splicing, facilitating gene discovery, and as regulators of nucleic acid-based therapeutics, including next-generation gene therapy.

Due to the limited understanding of context-dependent structure-function relationships, the identification of functional riboswitch devices can be significantly advanced by large-scale-screening of aptamer-effector-domain designs. The latter is often impeded by the lack of appropriate cellular highthroughput methods.

High-throughput identification of synthetic riboswitches. A fast and broadly applicable method was recently described to functionally screen complex riboswitch libraries in a cellular high-throughput approach. The authors used cDNA-ampliconsequencing to count conditionally expressed mRNAs in transiently transfected and ligand-stimulated human cells. ${ }^{131}$ In contrast to other methods, the new self-barcoding strategy of each riboswitch library member avoided the need for additional cDNA-manipulation steps to introduce external sequencing barcodes. This method was demonstrated for engineering of guanine- and tetracycline-responsive off- and on-switches utilizing twister, hepatitis delta virus, and hammerhead ribozymes as well as U1-snRNP polyadenylation-dependent RNA devices.

Towards the identification of cofactor-based RNA methylation tools - impact on RNA epitranscriptomics, and the RNA world hypothesis. Despite intensive research on allosteric RNA devices, examples that involve advanced chemical reactions such as methylations based on binding of a biological methylation agent (e.g. SAM, methyl cobalamin, or methylene tetrahydrofolate) to RNA aptamer domains and subsequent reaction using the bound cofactor have not yet been identified. Given the large number of naturally occurring methylated nucleosides in tRNA, rRNA, snRNA, and mRNA, the assumption of a potential existence of catalytic RNA with methyltransferase activity is intriguing. Thus far, only self-alkylation reactions involving $\alpha$-iodo- or $\alpha$-chloroacetamide moieties, ${ }^{132-134}$ or more recently, epoxide ring-opening ${ }^{135}$ were successfully utilized for in vitro selection of RNA biotinylation and labelling tools, although the reaction times were up to 48 hours to give yields below 50\%. ${ }^{135}$ 
A
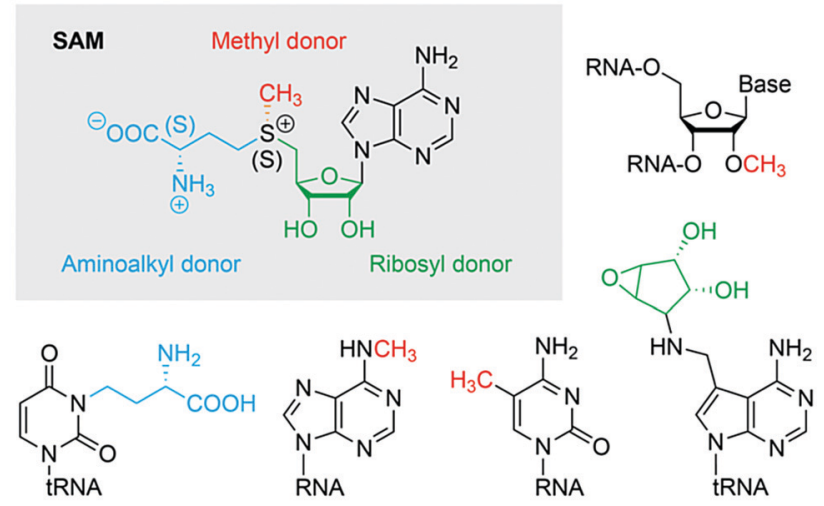

B
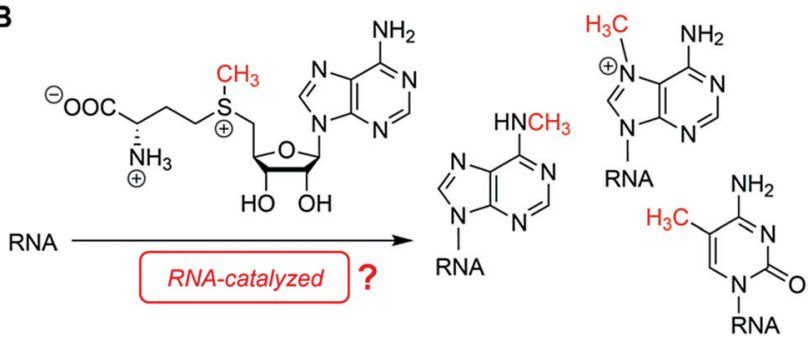

Fig. 4 S-Adenosylmethionine (SAM). (A) Chemical structure of the cofactor and known reactivities (grey shadow) and protein-enzyme mediated reaction products of SAM with RNA targets. (B) Hypothesis for RNAcatalysed methylation reactions using SAM as cofactor in a prebiotic RNA world.

RNA harbours all structural and functional requirements to bind small molecules and to catalyse more complex chemical reactions beyond phosphodiester cleavage. In particular, the identification of RNA methylation tools seems to be at hand, however, this has not yet been demonstrated, neither by in vitro selection, nor by identification of an existing cellular system (Fig. 4). Finding evidence for both would have a tremendous impact on the RNA world hypothesis and prebiotic chemistry, on RNA epitranscriptomics, and on biotechnological RNA tool development.

\section{Catalytic nucleic acids - ribozymes \& DNAzymes}

Both RNA and DNA can fold into structures that catalyse chemical reactions. For naturally occurring systems, these reactions mostly concern RNA phosphodiester cleavage and ligation, besides peptide bond formation in the peptidyl transferase center of the ribosome, ${ }^{136}$ while no examples for naturally occurring catalytic DNAs are known thus far. ${ }^{137,138}$ With respect to in vitro selected RNA and DNA, the scope of reactions that can be catalysed is much broader, including N7 alkylations (mentioned above), ${ }^{132,135}$ aminoacylations, ${ }^{26,139,140}$ Michael additions, ${ }^{141}$ Diels-Alder reactions, ${ }^{142,143}$ and many more. ${ }^{137,144}$

Below we will focus on recent developments in the field of phosphodiester-cleaving and -forming ribozymes and DNAzymes only.

\section{Small self-cleaving ribozymes}

The first ribozymes were discovered by Thomas Cech and Sidney Altman in the eighties and this finding changed the paradigm that proteins were the sole catalytic molecules in living organism. Earlier, RNA was considered to be information carrier (messenger RNA, mRNA), structural scaffold of the ribosome (ribosomal RNA, rRNA), and interface between them as amino acid transporter and decoder (transfer RNA, tRNA). RNA's functions, however, go well beyond these tasks, and ribozymes represent one important class of naturally occurring functional RNAs. Most of them catalyse RNA backbone cleavage or the converse, RNA ligation. Ribozymes can be grouped into splicing ribozymes and cleaving ribozymes, ${ }^{145}$ with the latter divided further into trans-cleaving ribonuclease $\mathrm{P},{ }^{146}$ and small self-cleaving (or 'nucleolytic') ribozymes. To date, nine distinct small self-cleaving ribozyme classes have been described, including hairpin, ${ }^{147-150}$ hammerhead, ${ }^{151-155}$ hepatitis delta virus (HDV) and HDV-like motifs, ${ }^{156-159}$ glucosoamine-6-phosphate synthase $(\mathrm{g} l \mathrm{~lm} S),{ }^{117,160,161}$ and Neurospora Varkud satellite (VS). ${ }^{162,163}$ More recently, twister, ${ }^{164}$ twister sister, ${ }^{165}$ hatchet, ${ }^{165}$ and pistol $^{165}$ motifs have been added.

Concerning the biological function of small self-cleaving ribozymes in living systems, rather little is known. ${ }^{166}$ For instance, HDV ribozymes promote their own cleavage from the transcript during rolling circle replication of the hepatitis delta virus. Also hairpin and VS ribozymes are connected to viral genome replication. ${ }^{167}$ The function of hammerhead ribozymes with thousands of representatives in diverse organisms is less clear. A role during pre-mRNA biosynthesis is conceivable but other putative biological functions are mainly linked to the genomic context and hence remain speculative. ${ }^{166}$

Numerous chemical, biochemical, and biophysical studies have been performed, that can be compared and contrasted with structural studies of most ribozymes, usually based on X-ray crystallography. ${ }^{166-173}$ Small self-cleaving ribozymes conduct site-specific internal transesterification which involves the ribose 2 -hydroxy group adjacent to the scissile phosphate. Through a $\mathrm{S}_{\mathrm{N}} 2$-type mechanism, a penta-coordinated phosphorane transition state is passed, ${ }^{174}$ and finally results in two products. The product RNA $5^{\prime}$ of the scissile phosphate retains this phosphate in form of a $2^{\prime}, 3^{\prime}$-cyclic phosphate while the $3^{\prime}$ RNA product obtains free hydroxyl termini. To support the reaction, the ribozyme can engage up to four potential strategies (Fig. 5). ${ }^{175-177}$ First, the $2^{\prime}$-oxygen, phosphor, and $5^{\prime}$-oxygen atoms should ideally lie on a straight line for nucleophilic attack ( $\alpha$ catalysis); ${ }^{178}$ second, the enhanced negative charge on the nonbridging phosphate oxygens in the transition state should be electrostatically compensated ( $\beta$ catalysis); third, the proton from the attacking 2 '-OH nucleophile should be removed ( $\gamma$ catalysis - general base catalysis); and fourth, the developing negative charge on the $5^{\prime}$ oxygen leaving group should be neutralized by donating a proton $(\delta$ catalysis, general acid catalysis) (Fig. 5). Recently an advanced ontology was developed for discussion of these strategies that refines this established framework into primary, secondary, and tertiary 

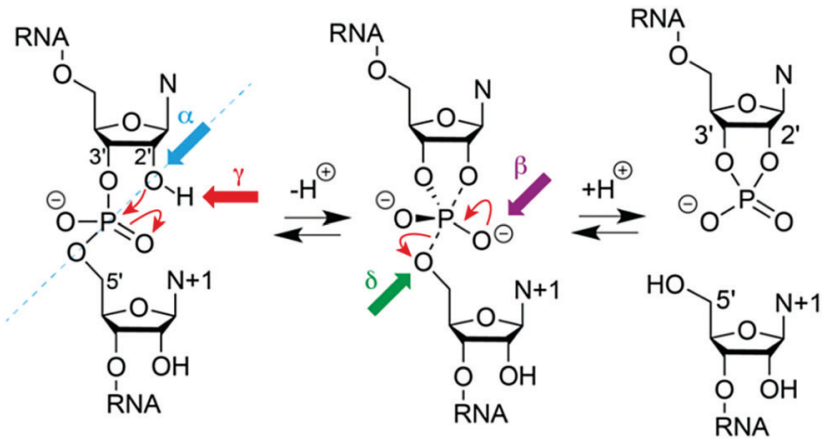

Fig. 5 Model for phosphodiester cleavage in small self-cleaving ribozymes. ${ }^{180}$ The to-be-cleaved ("scissile") phosphate is proposed to form a pentacoordinate transition state by $\mathrm{S}_{\mathrm{N}} 2$-like in-line attack of the nucleophilic $2^{\prime}$-hydroxy group ( $\alpha$ catalysis, blue); thereby, neutralization of the (developing) negative charge on nonbridging phosphate oxygen atoms ( $\beta$ catalysis, purple) may support, as well as deprotonation of the $2^{\prime}$-hydroxy group ( $\gamma$ catalysis, red) and/or neutralization of negative charge on the $5^{\prime}$-oxygen atom by protonation ( $\delta$ catalysis, green). The $5^{\prime}$ cleavage product carries the original phosphate in form or a $2^{\prime}, 3^{\prime}$-cyclic phosphate.

contributions to enable a more precise description of the reaction mechanism with respect to structure and bonding. ${ }^{179}$

Moreover, the cleavage of the phosphodiester bond is not necessarily concerted. The transesterification process can proceed stepwise involving transition states that are 'tight' and asynchronous. ${ }^{174,181}$ The individual architectures of the active sites encountered in distinct ribozyme classes determine the reaction pathway and transition states and these features are responsible for the broad range of cleavage rates, spanning several orders of magnitude $\left(<0.1 \mathrm{~h}^{-1}\right.$ to $\left.>1 \mathrm{~s}^{-1}\right)$.

For protein-based enzymes, the structurally distinct side chains of 21 amino acids provide sufficient diversity to contribute to reaction catalysis. ${ }^{176}$ In contrast, the four nucleosides in ribozymes offer a limited scope of functionalities that affects electrostatic catalysis and general acid-base catalysis at neutral $\mathrm{pH}$. Due to the fact that ionization of the nucleobases and the 2 '-OH of the ribose requires rather harsh acidic or basic conditions, the first reports thus suggested ribozymes to rather be metalloenzymes with the RNA serving as scaffold to place hydrated $\mathrm{Mg}^{2+}$ ions as effectors. ${ }^{182,183}$ Later, it was found that many self-cleaving ribozymes are functional in the absence of divalent metal cations. Experimental evidence was collected for $\mathrm{p} K_{\mathrm{a}}$-shifted active site nucleobases that participate directly in catalysis in some ribozymes, and nowadays, the general acidbase catalysis is a widely accepted concept for rate enhancement in small self-cleaving ribozymes. ${ }^{167,184}$ Nevertheless, direct effects of $\mathrm{pH}$ and metal ions on ribozyme catalysis are usually difficult to distinguish from indirect effects on folding (and fold stabilization) of a ribozyme and require advanced and careful experimentation. ${ }^{176}$

In the years 2014 and 2015, the ribozyme field was reinvigorated by two studies describing the identification of four novel ribozymes, termed twister, ${ }^{164}$ twister sister, ${ }^{165}$ pistol, ${ }^{165}$ and hatchet. ${ }^{165}$ These discoveries initiated comprehensive investigations applying modern experimental and computational approaches to further increase our understanding of ribozyme-mediated catalysis.

\section{Twister ribozyme}

Among the four most recently discovered ribozymes, twister has been investigated most intensively by biochemical, ${ }^{164,165,185}$ structural, ${ }^{186-189}$ and chemical ${ }^{189}$ approaches providing insights into the topological constraints contributing to catalysis. The clear distinctions observed in the active site and the P1 segment of the available crystal structures left room for miscellaneous interpretations and speculations. In particular, the observation of $\mathrm{Mg}^{2+}$ ions in inner-sphere coordination to the scissile phosphate in two of the structures caused debates on their relevance for catalysis (Fig. 6). ${ }^{190-192}$ Analysis of thio effects and metal ion rescues for phosphorothioate substrates assigned them a minor role. ${ }^{189,193}$ Key functions, however, can be attributed to conserved nucleosides in the active site, namely a guanine and the adenine directly at the cleavage site, both involved in general acid-base catalysis. Interestingly, for the adenine, the crucial site of protonation in its role of $\delta$ catalysis was narrowed down to the $\mathrm{N} 3$ position in the architectural framework of the ribozyme, distinct to the usually preferred N1 protonation site of adenosine. ${ }^{189,193,194}$

Another insightful perspective was provided by recent studies that analysed the $\delta$ catalysis role of this adenine via chemical rescue. ${ }^{195,196}$ Using inhibited twister ribozyme variants with 1- and 3-deazaadenosine modifications, the authors observed significant chemical rescue effects in the presence of small molecules such as imidazole and histidine. Brønsted plots for the twister variants supported a model in which small molecules rescue catalytic activity via a proton transfer mechanism, suggesting that the conserved adenosine directly at the cleavage site in the wild type is involved in proton transfer, most likely general acid catalysis. Additionally, it was demonstrated that an 8-bromoadenosine modified twister ribozyme is faster than a native counterpart, supporting crystallographic data that show that this adenosine is in syn conformation when conducting proton transfer.

A further peculiarity of twister is that it retains wild-type activity when the phylogenetically conserved stem P1 is deleted, able to cleave a single nucleotide only. ${ }^{189}$ This feature was already insinuated by the crystal structures of twister, with two of them showing a fully base paired P1 stem (Fig. 6G) whereas two others showed disrupted base pairs instead, with two of the nucleobases participating through fold back in formation of stacked base triples (Fig. 6F). ${ }^{190,192}$ A singlemolecule FRET study on twister ribozyme folding rationalizes this behaviour by revealing that the active site-embracing pseudoknot fold is preserved in the P1-lacking ribozyme and in the cleaved $3^{\prime}$-product RNA where P1 cannot form (Fig. 7). ${ }^{197}$ The rigid fold of the cleaved 3 -fragment that retains its compacted pseudoknot fold despite the absence of stem P1 is furthermore consistent with the poor turnover efficiency of the twister ribozyme. Taken together, the phylogenetically conserved stem P1 is not only dispensable for cleavage activity but also for folding into the active structure. The reason for P1 conservation remains unclear and very likely concerns features other than chemical mechanism and formation of the cleavagecompetent ribozyme fold. 


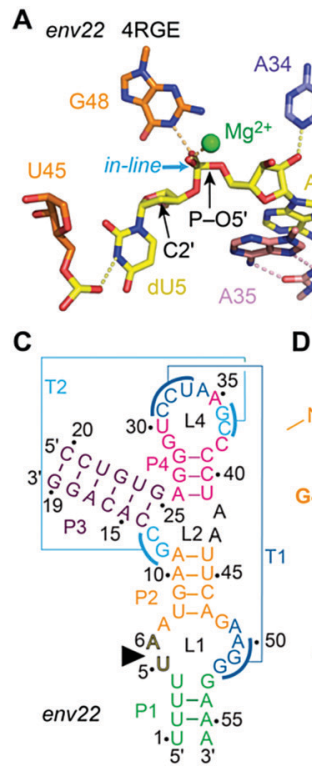

$\mathbf{F}$

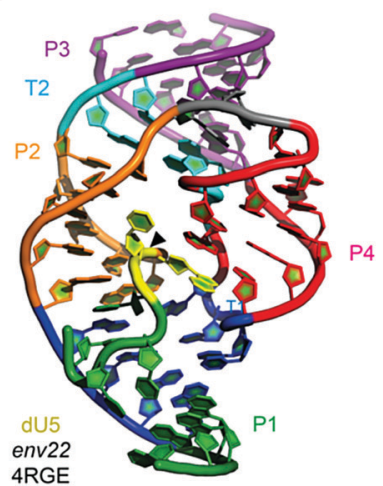

B O. sativa 4OJI $2.3 \AA$

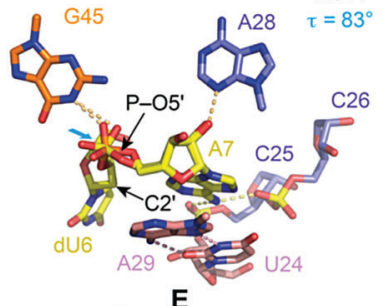

D

E

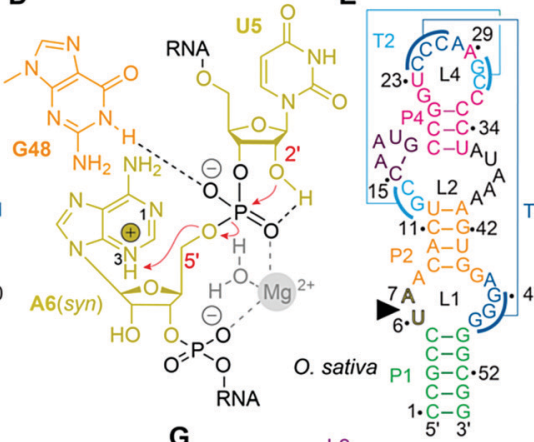

G

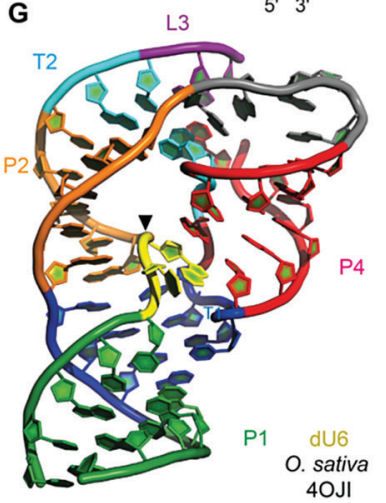

Fig. 6 Twister ribozyme. (A) Pocket for dU-A active site in the $2.9 \AA$ resolution structure of the env22 twister ribozyme with emphasis on the position of the $\mathrm{C}^{\prime}$ of $\mathrm{dU}$ relative to the $\mathrm{P}-\mathrm{O}^{\prime}$ bond. (B) Pocket for $\mathrm{dU}-\mathrm{A}$ active site pocket in the $2.3 \AA$ resolution structure of the $O$. sativa twister ribozyme. (C) Secondary structure model of env22 ribozyme. (D) Current model for the twister cleavage mechanism; major roles G48 ( $\gamma$ catalysis) and $A 6$ ( $\delta$ catalysis via N3), minor role: hydrated $\mathrm{Mg}^{2+}$. (E) Secondary structure model of $O$. sativa ribozyme. (F) Three-dimensional structure in cartoon presentation of the $\mathrm{dU}$ modified env22 ribozyme and $(\mathrm{G})$ the $\mathrm{dU}$ modified $O$. sativa ribozyme. Note the differences in segment P1 (green): 'back-folding' of nucleosides (U1 and U4) of segment P1 for env22 to form base triplets, and fully Watson-Crick base-paired stem P1 for O. sativa, respectively. Black triangles indicate the cleavage positions.

Finally, a series of computational studies have followed and further described this ribozyme, essentially supporting the above mentioned experimental findings and interpretations. ${ }^{198-201}$

\section{Pistol ribozyme}

For the pistol ribozyme, our understanding of the catalytic mechanism of phosphodiester cleavage has grown significantly over the past years (Fig. 8A). Initial structural and biochemical data hinted primarily at a general acid-base mechanism involving purine nucleobases in the active site. ${ }^{165,202-204}$ Later, this view was expanded because intensive atomic mutagenesis-based assays shed light on the mechanistic role of divalent metal ions. ${ }^{205,206}$

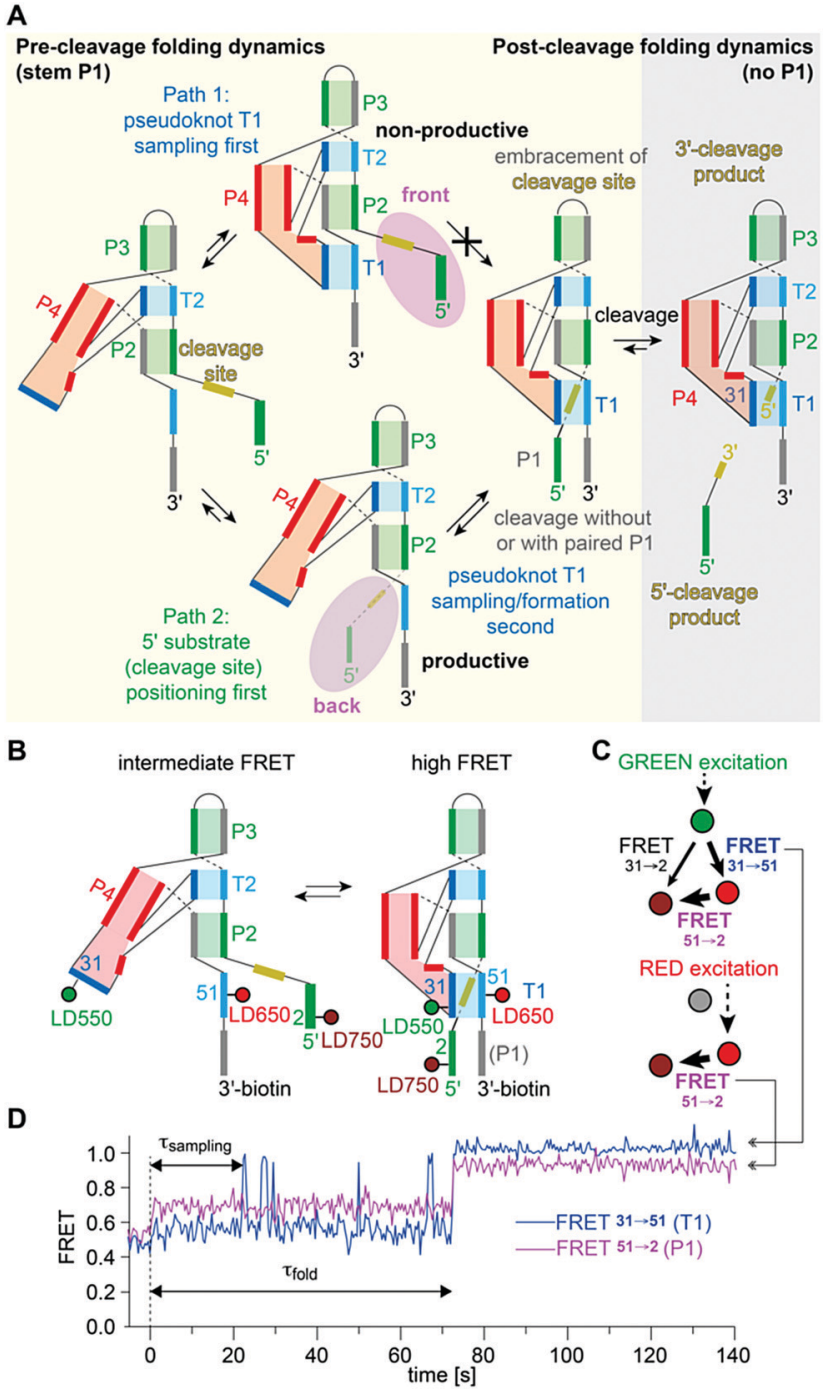

Fig. 7 Twister ribozyme. (A) Alternative folding pathways to achieve the catalytically active pseudoknot fold as derived from a comprehensive 2- and 3-color FRET study based on a series of probes with distinct label positions. ${ }^{197}$ (B) Labelling pattern and cartoon of anticipated dynamics. (C) Schematics of alternating laser excitation (ALEX) experiments. (D) Representative FRET time course after stopped-flow $\mathrm{Mg}^{2+}$ addition (dotted line indicates $2 \mathrm{mM}$ final concentration).

The first three-dimensional structures of the pistol ribozyme were available in 2016, solved by X-ray crystallographic methods with a resolution of $2.7 \AA$ (env25 pistol $)^{203}$ and $3.0 \AA$ (env27 pistol), ${ }^{204}$ respectively. Both structures represent a precatalytic conformation that has been trapped based on mutants carrying a hydrogen atom instead of the native $2^{\prime} \mathrm{OH}$ nucleophile at the cleavage site. Moreover, the two structures are in very good agreement with respect to the overall topology and the cleavage site alignments and implied nucleobase-mediated acidbase catalysis of the cleavage reaction, ${ }^{192}$ involving a guanine (G40) and seemingly, an adenine (A32) in the active site. Shortly after, a chemical study based on atomic mutagenesis demonstrated that $\mathrm{a} \mathrm{Mg}^{2+}$ ion that is innersphere-coordinated to the N7 atom of another guanine in the active site (G33) plays a key 
role in catalysis (rather than A32). ${ }^{205}$ The disruption of this coordination site by N7-to-C7H mutation caused a 1000-fold decrease in cleavage rate. This was reconfirmed by an independent study. ${ }^{207}$

Very recently, additional crystal structures have been published, providing three-dimensional snapshots that now cover further states along the reaction coordinate of pistol phosphodiester cleavage, representing the transition state (in form of a vanadate mimic) (Fig. 8B) and the product $\left(2^{\prime}, 3^{\prime}\right.$ cyclophosphate). ${ }^{206}$ This broad structural foundation resulted in a profound proposal of the underlying chemical mechanism. Essentially, a hydrated $\mathrm{Mg}^{2+}$ ion remains innersphere-coordinated to the N7 nitrogen of G33 in all three states, which supports its proposed role as acid in general acid base chemistry ( $\delta$ and $\beta$ catalysis). ${ }^{206}$ Interestingly, a second hydrated $\mathrm{Mg}^{2+}$ ion approaches the to-be-cleaved phosphate from its binding site in the pre-cleavage state to stretch out for water-mediated hydrogen bonding to one of the non bridging oxygen atoms of the cyclophosphate product. ${ }^{206}$ The major role of the second $\mathrm{Mg}^{2+}$ ion appears to be stabilization of the product conformation.

Combined mechanistic scenario for pistol cleavage. In the precatalytic pistol conformation, a divalent ion $\left(\mathrm{Mg}^{2+}\right)$ becomes innersphere-coordinated to the N7 atom of guanine G33 in the active site and is further fixated by first shell water-mediated hydrogen bonds, one to the 2 -hydroxy group of the ribose in position 32 (with highly conserved purine base; A or G), and the other one to the pro- $R$ oxygen of the scissile phosphate (Fig. 8C). Simultaneously, guanine G40 triggers proton transfer from the 2'-hydroxy group of G53 which attacks the adjacent phosphorus atom in-line to the $\mathrm{P}-\mathrm{O}^{\prime}$ bond. Of note, a second divalent $\mathrm{Mg}^{2+}$ ion (in a binding site formed by A38 and A39) comes $3.9 \AA$ close to the $\mathrm{O} 6$ of $\mathrm{G} 40$ and could in principle impact the $\mathrm{p} K_{\mathrm{a}}$ of guanine $\mathrm{G} 40$, however, mutation of G40 to 2-aminopurine (lacking O6) did not hamper wild-type activity. In the transition state, the nucleobase of G40 stabilizes the phosphorane in a bidendate manner (via $\mathrm{N} 1 \cdots 2^{\prime} \mathrm{O}$ and $\mathrm{N} 2 \cdots$ pro- $R \mathrm{O}$ ), and at the same time, the proximity of the divalent ion that remains innersphere-coordinated to N7 of G33 likely lowers the energy barrier by electrostatic interactions and by outershell coordination to the pro- $R$ nonbridging oxygen atom of the to-be-cleaved phosphate (Fig. 8C). This process, in turn, locates one of its first shell water molecules (general acid) into suitable distance for proton transfer to the $5^{\prime} \mathrm{O}$ leaving group. The obtained cyclophosphate becomes embedded in a network of hydrogen bonds involving the two hydrated $\mathrm{Mg}^{2+}$ ions coordinated to the pro- $R$ and pro- $S$ oxygen atom, respectively. This assembly may stabilize a cyclophosphate conformation that blocks ligation of the cleaved fragments (reverse reaction). Interestingly, one of the hydrated $\mathrm{Mg}^{2+}$ ions moves from its A38/A39 binding site in the pre-cleavage state towards the cyclophosphate moiety in the post-cleavage state while the other hydrated $\mathrm{Mg}^{2+}$ ion remains strictly positioned at the N7 of G33 in all three states for executing its role in $\delta$ and $\beta$ catalysis (Fig. 8D).

Comparison to other ribozymes with transition state structures. Only two other ribozymes have been previously characterised by
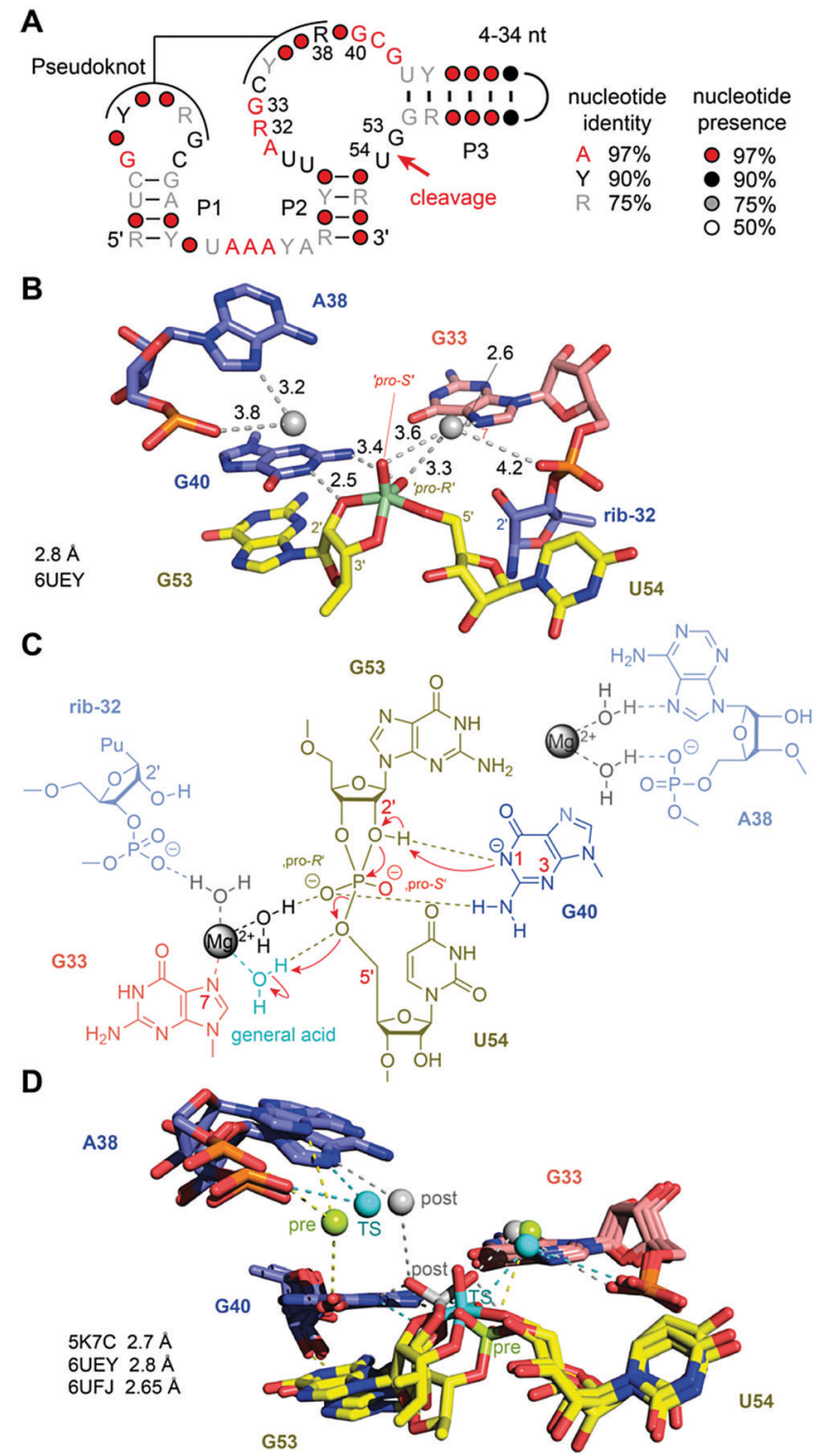

Fig. 8 Pistol ribozyme. (A) Secondary structure model of the consensus sequence. (B) Pocket for active site G53-U54 observed in the crystal structure of a vanadate transition state mimic. Crucial atom distances (below $4.5 \AA$ ) that indicate direct or water-mediated hydrogen bonds and/ or metal ion interactions are shown by dashed lines. The values in black are distances in $\AA$. Note that the number of distances can exceed the number of possible hydrogen bonds for an atom. (C) Current model for pistol cleavage mechanism; major roles G40 ( $\gamma$ catalysis) and hydrated $\mathrm{Mg}^{2+}$ coordinated to N7-G33 ( $\delta$ catalysis), minor role: hydrated $\mathrm{Mg}^{2+}$ coordinated to $A 38$. (D) Superpositions of the pre-cleavage state $\left(\mathrm{M}^{2+}\right.$ and scissile phosphate in green color), TS analogue vanadate (cyan), and postcleavage state (grey), revealing the repositioning of the $\mathrm{Mg}^{2+}$ ion close to $\mathrm{O} 6$ of G40 in the pre-cleavage state towards the pro-S oxygen atom of the scissile phosphate in the cyclophosphate product.

crystallography of transition state analogues. Using vanadium oxide as mimic was pioneered for the hairpin ribozyme. ${ }^{150}$ Direct interactions with the nucleobase, which seemed to stabilize the electronic structure and geometry of the hairpin ribozyme TS, had been revealed, ${ }^{150}$ as well as potentially involved water molecules ${ }^{208}$ Similar to pistol, the superposition of pre-cleavage, 


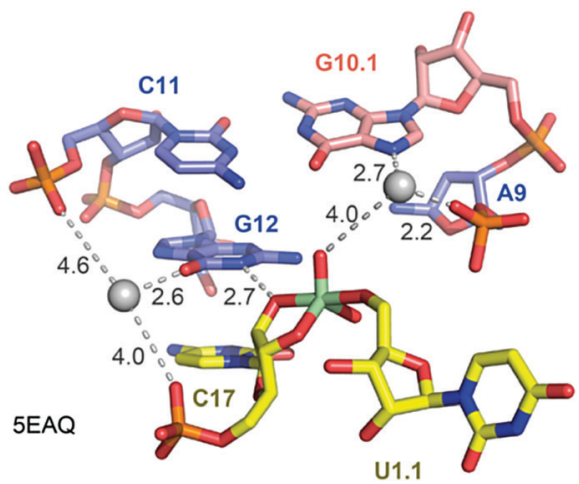

Fig. 9 Hammerhead ribozyme. Pocket for active site C17-U1.1 (transition state mimic; vanadate) for purposes of comparison with the pistol ribozyme pocket. Crucial atom distances indicating possible interactions are shown by dashed lines. The values in black represent distances in $\AA$.

transition state mimic, and product structures of the hairpin ribozyme displayed that the active site was rigid, while motion concerned the scissile phosphate and the upstream nucleoside sugar pucker. In contrast to the pistol ribozyme, no divalent metal ion was observable in the active site of the hairpin ribozyme and only nucleobases participated in the recognition of the cleavage site.

Not long ago, the three-dimensional structure of a hammerhead ribozyme (HHRz) TS analogue was described. ${ }^{155}$ This vanadate complex revealed important rearrangements compared to the earlier obtained pre-cleavage HHRz structures. The active site contracted, placing a guanine (G10.1) closer to the cleavage site (Fig. 9). This guanine appears similar to G33 in the pistol ribozyme because it coordinates a divalent ion through N7 and a backbone phosphate (A9). Although the distance to the scissile phosphate is farther compared to the arrangement in pistol, the HHRz vanadate structure also suggested a stabilization of the transition state by water-mediated H-bonding with the scissile phosphate. A second divalent ion was found in innersphere coordination to $\mathrm{O} 6$ of a guanine (G12). This guanine fulfills the role of a general base in the hammerhead ribozyme active site with the metal ion tuning the $\mathrm{p} K_{\mathrm{a}}$ value to support deprotonation of the attacking $2^{\prime}-\mathrm{OH}$ of C17. Importantly, the deletion of O6 in a G12Ap mutant of the hammerhead ribozyme was responsible for a significant rate reduction (by a factor of $\left.10^{3}\right),{ }^{209}$ and this finding underlines the importance of innersphere coordination of the metal ion to this atom. Distinct to HHRz, the role of the second $\mathrm{Mg}^{2+}$ with respect to pistol cleavage acceleration is minor, however, it appears to stabilize the conformation of the cyclophosphate product in the complex.

\section{Twister-sister ribozyme}

The twister-sister ribozyme adopts either a three-way or four-way junctional fold comprising internal and terminal loops with conserved residues resembling those in the twister ribozyme (Fig. 10A). ${ }^{165}$ Self-cleavage occurs between cytidine (C62) and an adenosine (A63) of an internal loop that is on the opposite side when compared to the twister ribozyme secondary structure model.

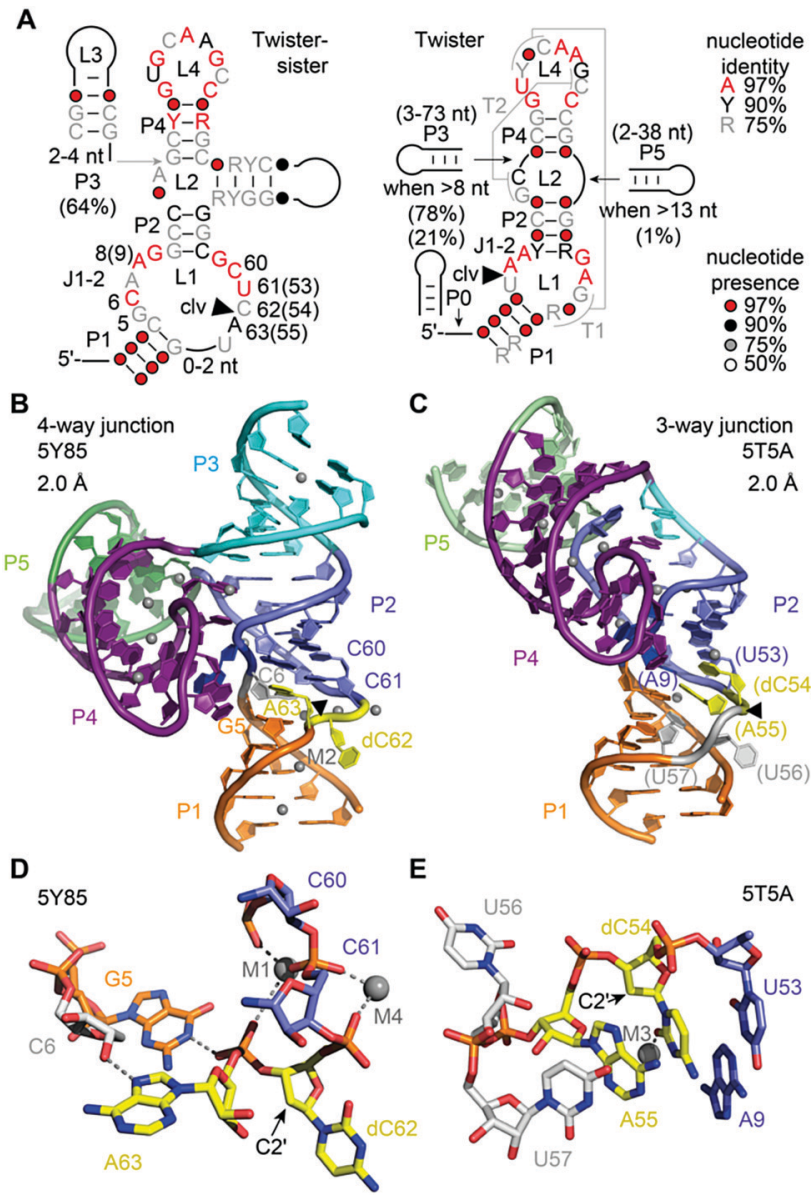

Fig. 10 Twister-sister ribozyme. (A) Secondary structure model of the consensus sequence of twister-sister (left) and comparison to twister (right). (B) Three-dimensional structure in cartoon presentation of the $\mathrm{dC}$ modified 4-way junctional (4WJ) ribozyme and (C) the dC modified 3-way junctional (3WJ) ribozyme. Note the differences at the cleavage site (yellow): splayed apart (dC62 and A63) for 4WJ, and stacked in double helix (dC54 and A55) for 3WJ. Black triangles indicate the cleavage positions. (D) Pocket for dC-A active site in the 2 structure of the $4 \mathrm{WJ}$ ribozyme with emphasis on the G5-scissile phosphate interaction. (E) Pocket for $\mathrm{dC}-\mathrm{A}$ active site pocket in the structure of the $3 \mathrm{WJ}$ ribozyme.

To date only two structures exist of this ribozyme, representing the precatalytic state (Fig. 10B and C). ${ }^{210,211}$ Both structures display the terminal loop with a high number of conserved nucleotides projecting from a large continuous helical fold onto the minor groove of the partially zippered-up internal L1 loop segment associated with a second continuous helix (Fig. 10B and C). The two structures, however, show significant distinctions in the active site arrangement (Fig. 10D and E).

For the four-way junctional fold, the bases $\mathrm{C}$ and $\mathrm{A}$ at the cleavage site are splayed apart. The $\mathrm{C}$ is directed outwards and A directed inwards and held tightly within the ribozyme core (Fig. 10D). ${ }^{210}$ Remarkably, the modeled $2^{\prime}-\mathrm{OH}$ is far from adopting an ideal angle for in-line attack at the scissile phosphate. Importantly, the N1H of an active pocket guanine (G5) and an innersphere water of a hydrated $\mathrm{Mg}^{2+}$ cation (labeled M1 in Fig. 10D) form hydrogen bonds to the non bridging phosphate oxygens, fixating the scissile phosphate. In addition, 
a second hydrated $\mathrm{Mg}^{2+}$ (labeled M2 in Fig. 10B) is located in a way that an innersphere water is in hydrogen bond distance of the (modeled) 2'-O nucleophile of C. Mutations of the active pocket guanine and inwardly-oriented and anchored active site adenine abolish cleavage, while mutations of the flexible and outwardly-oriented cytosine have no influence on activity.

In the three-way junctional fold, the in-line conformation required for attack of the $2^{\prime}-\mathrm{OH}$ at the scissile phosphate is also not adopted (Fig. 10E). ${ }^{211}$ Interestingly, the $2^{\prime}-\mathrm{OH}$ nucleophile is within hydrogen bonding distance of an innersphere water of a hydrated $\mathrm{Mg}^{2+}$ cation (labeled M3 in Fig. 10E). Furthermore, the $\mathrm{C}$ and $\mathrm{A}$ are stacked, and $\mathrm{C}$ adopts a fixated and $\mathrm{A}$ a flexible arrangement in the three-way junctional structure, ${ }^{211}$ unlike to the alignments of $\mathrm{C}$ and $\mathrm{A}$ in the four-way junctional structure. ${ }^{210}$ Moreover, the oxygens of the scissile phosphate do not interact with a $\mathrm{G}$ and also not with a hydrated $\mathrm{Mg}^{2+}$ in the three-way junctional structure, ${ }^{211}$ as it is in the four-way junctional structure. ${ }^{210}$ These stark differences observed for the catalytic pocket of the pre-catalytic states attest the necessity for further studies that reveal the architecture of transition state mimics of the twister-sister ribozyme at high resolution to shed light on the chemical mechanism.

Based on the structure of the $3 \mathrm{WJ}$ twister-sister ribozyme, a model for the functional active state of the ribozyme from molecular simulation proposed either direct or $\mathrm{Mg}^{2+}$ mediated involvement of a cytosine (C7) in the active site pocket for the cleavage reaction. $^{212}$

\section{Hatchet ribozyme}

The hatchet motif is unusual because its cleavage site is located at the very $5^{\prime}$ end of its secondary structure model. ${ }^{165,185,212}$ The only other ribozymes that are wholly downstream of their cleavage sites are the HDV family of ribozymes ${ }^{213}$ and the glmS riboswitch-ribozyme, keeping in mind that the latter is dependent on the cofactor GlcN6P for its activity. ${ }^{160,161}$

The hatchet ribozyme sequence contains thirteen highly conserved residues interspersed amongst bulge elements linking stem segments but no obvious tertiary interactions could be deduced from the biochemical data alone. ${ }^{185,212}$ RNA strand scission in the hatchet ribozyme requires divalent $\mathrm{Mg}^{2+}$ cations. The maximum cleavage rate $k_{\text {obs }}$ was determined to approx. $4 \min ^{-1}$, reaching a plateau on increasing the $\mathrm{pH}$ to 7.5. Rate measurements on scissile phosphorothioate analogues suggested a crucial contact between the scissile phosphate and a functional group in the active site of the ribozyme. ${ }^{214}$ Moreover, the $\mathrm{pH}$ reactivity profile was determined and implied that the attacking $2^{\prime}-\mathrm{OH}$ is activated by a functional moiety that has a $\mathrm{p} K_{\mathrm{a}}$ value of about $7 .^{214}$

To date, only one crystal structure of a hatchet ribozyme is available, representing the post-cleavage state (Fig. 11). ${ }^{215}$ The ribozyme crystallised as dimer with strand swap in the $3^{\prime}$-end region. Mutations in the $4 \mathrm{nt}$ dimerisation site revealed that the monomeric form is fully active. The hatchet ribozyme comprises a pair of two parallel-aligned long helices P2-P1 (H12) and P3-L3-P4 (H34) (Fig. 11A). The long-distance interaction between terminal loop L1 and internal loop L3 identified in

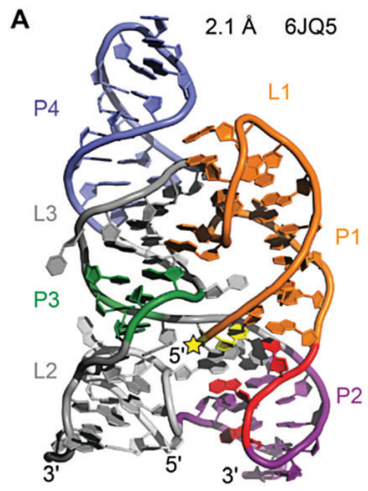

D

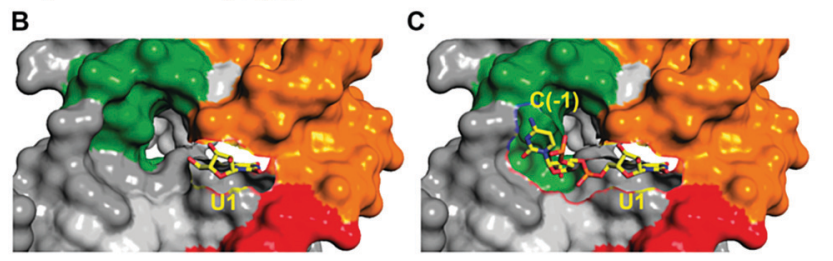

Fig. 11 Hatchet ribozyme. (A) Three-dimensional fold in cartoon presentation of the ribozyme product (post-cleavage state). The site of cleavage is labeled with a yellow star. (B) The ribozyme product is shown in surface representation with $\mathrm{U} 1$ in sticks (yellow). A cavity is visible adjacent to the leaving group $5^{\prime}-\mathrm{OH}$ of $\mathrm{U} 1$ which seems of sufficient size to accommodate the scissile phosphate and a nucleoside $5^{\prime}$ of it. (C) Model of the hatchet ribozyme comprising the $\mathrm{C}(-1)-\mathrm{U} 1$ cleavage site shown in sticks (yellow) and otherwise in surface representation. $C(-1)$ was modeled based on the shape of the cavity on the hatchet ribozyme surface. (D) The proposed model for the precatalytic state of the ribozyme, in which $C(-1)$ forms extensive hydrogen bonds with nucleosides and the phosphate backbone in the pocket. The modelled conformation is in-line and indicates functional groups of nucleotides that may contribute to catalysis. In particular, N7 of G31 is a candidate based on the finding that a 7-deaza-G31 mutant was inactive.

the tertiary fold, together with several bridged nucleotides in internal L2, appear to anchor the relative alignments of H12 and $\mathrm{H} 34$.

Despite the cleavage site being located at the $5^{\prime}$ end of the sequence, it is positioned in the center of the tertiary structure of the hatchet ribozyme (Fig. 11A). ${ }^{215}$ Moreover, the dispersed conserved nucleotides in the secondary structure of the hatchet ribozyme are all brought into proximity and aligned around the cleavage site. Their alignments result in the generation of a pocket with the leaving group $5^{\prime}-\mathrm{OH}$ of $\mathrm{U} 1$ pointing toward the cavity (Fig. 11B). The dimensions of the pocket are capable of accommodating both the (modeled) $\mathrm{C}(-1)$ and the scissile phosphate linked to $\mathrm{U} 1$ (Fig. 11C). The $\mathrm{C}(-1)$ and $\mathrm{U} 1$ are splayed apart and the $2^{\prime}-\mathrm{OH}$ is ideally positioned for an in-line attack at the scissile phosphate (Fig. 11D). The model further highlights likely interactions of $\mathrm{C}(-1)$ and the to-be-cleaved phosphate with functional groups of nucleosides in the pocket which are potential candidates for general base and general acid catalysis. In particular, this concerns a G of a conserved G-C base pair (G31-C64) whose mutation to 7-deazaguanine renders the ribozyme inactive. To gain deeper insights into hatchet catalysis, structure determination of precleavage and transition state mimics are needed. 
Comparison of hatchet and HDV ribozymes. Only one other ribozyme class is known with the cleavage site at the very $5^{\prime}$ end of its consensus sequence, namely the HDV family of ribozymes. ${ }^{213}$ Similar to hatchet, the first crystal structure of an HDV RNA was solved for the cleaved product. ${ }^{157}$ The HDV ribozyme comprises five helical regions that are arranged in a nested double pseudoknot, forming two coaxial stacks (Fig. 12A). The parallel alignment of these two long stacks is comparable to the hatchet ribozyme, although its helical composition is distinct. Moreover, the cleavage sites of both ribozymes (yellow star in Fig. 11A and 12A) are located in the center of each tertiary fold and the active site formation involved junctional regions. Another obvious similarity of hatchet and HDV active sites is that their $5^{\prime}$-terminal nucleosides (nucleoside $3^{\prime}$ from the scissile phosphate) are Watson-Crick base paired at the terminus of a stem (Fig. 12B and C).

The first HDV ribozyme structure pointed at a nucleoside (C75) in its active site pocket that was later ascertained to play a key role in catalysis. The hatchet product structure now points at a specific guanine (G31) in its pocket. Whether this nucleoside participates in general acid-base catalysis has yet to be determined. In the product structures of both ribozymes, no $\mathrm{Mg}^{2+}$ ions were identified in the vicinity of the cleavage site. However, the crystal structures of the pre-cleavage state that followed for HDV RNA later on, revealed $\mathrm{a} \mathrm{Mg}^{2+}$ ion in the pocket. ${ }^{216,217}$ Today the general view is that the protonated C75 of HDV is directly interacting with the scissile phosphate during the cleavage process, ${ }^{218}$ which is additionally supported by electrostatic interactions with the metal ion bound in the active site. $^{216-220}$

\section{RNA-cleaving deoxyribozymes}

The first DNA enzyme with endoribonuclease activity was identified by Breaker and Joyce using in vitro selection in $1994 .^{221}$
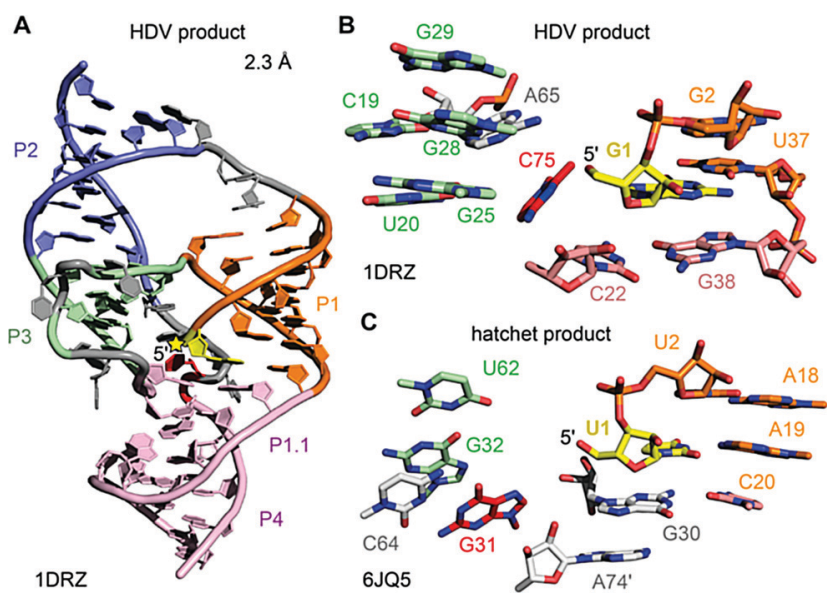

Fig. 12 HDV ribozyme. (A) Three-dimensional fold in cartoon presentation of the HDV ribozyme product (post-cleavage state). The site of cleavage is labeled with a yellow star. (B) Pocket of the HDV cleavage site with G1 shown in sticks (yellow). C75 (red) acts as general acid in $\delta$ catalysis. (C) Pocket of the hatchet cleavage site with U1 shown in sticks (yellow). G31 (red) has been proposed to play a crucial role in catalysis. Its precise role remains to be determined.
Since then, numerous examples of RNA-cleaving DNA enzymes have been reported, all of them derived from synthetic DNA libraries. ${ }^{222,223}$ Up to now, no natural catalytically active DNA has been found. RNA-cleaving DNA enzymes are practically useful tools for fundamental biochemical research, ${ }^{224}$ and deoxyribozymes have been explored as mRNA-targeting agents for the downregulation of disease-relevant genes (before the advent of other potent gene regulation approaches such as RNAi and CRISPR/Cas strategies). ${ }^{225}$ The largest and most diverse field of applications is found in bio- and nanotechnology, where DNAzymes are used as components of analytical devices for biosensors and logic gates. ${ }^{226-228}$ Recent reviews summarize diverse metal ion-dependent transesterification DNA enzymes and their applications. $^{228-230}$ In many analytical applications, the substrate is a DNA strand with a single ribonucleotide incorporated, linked to a FRET pair, with donor and acceptor placed before and after the cleavage site. ${ }^{231}$ A DNA sequence with a single ribonucleotide was also used as a substrate for in vitro selections that aimed at generalizing the substrate sequence tolerance at the cleavage site. ${ }^{232,233}$ Nearly all 16 dinucleotide junctions can now be cleaved, but only few DNA enzymes were tested on all-RNA substrates. Compared to the single-ribonucleotidecontaining substrate, significantly reduced cleavage rates and yields were observed. ${ }^{24}$ Nevertheless, interesting analytical applications have been reported, including quantitative analysis of $\mathrm{Na}^{+}$ion concentrations in cells. ${ }^{234}$ Below, we summarize structural and mechanistic aspects of RNA-cleaving DNA enzymes, and discuss recently reported DNA enzymes for the detection of posttranscriptional RNA modifications.

Structure and mechanism of the 8-17 DNA enzyme. Mechanistically, the best-characterised RNA-cleaving deoxyribozyme is the 8-17 DNAzyme. ${ }^{235,236}$ The structure of 8-17 in complex with a non-cleavable substrate analogue (i.e. a DNA strand) was reported in $2017 .^{237}$ To facilitate crystallisation, the DNA was complexed with a DNA polymerase protein derived from the African swine fever virus (AsfvPolX). The protein was found to bind to the outer extremities of the binding arm duplexes, in distant location from the active site (Fig. 13).

The structure revealed a surprising twisted pseudoknot in the catalytic core, with long-range base-pairing interactions that could not be predicted from a large set of biochemical data. $^{222,236}$ The pseudoknot contains very short base-paired regions, of 3 and 2 bp respectively. The 2 bp interaction consists of the Watson-Crick base pair G6-C12 and a non-canonical Hoogsten-sugar edge base pair A5-G13. The pseudoknot architecture positions the guanine G13 to serve as a general base to activate the $2^{\prime}-\mathrm{OH}$ by proton abstraction (not present in the structure), consistent with biochemical data. ${ }^{238}$ Divalent metal ions are essential for activity of $8-17$, with $\mathrm{Mg}^{2+}$ and $\mathrm{Mn}^{2+}$ as the most common cofactors for practical use. ${ }^{224}$ Interestingly, $\mathrm{Pb}^{2+}$ has been shown as the most active metal ion for 8-17 activation. ${ }^{239}$

The structure of $8-17$ was solved with $\mathrm{Pb}^{2+}$, and a partially occupied metal ion binding site was found that suggests interaction with $\mathrm{O}^{6}$ and/or N7 of $\mathrm{G} 6$ and with the nonbridging phosphate oxygen atoms, likely via water-mediated contacts in the hydration shell. Evidence for general acid-base 
A
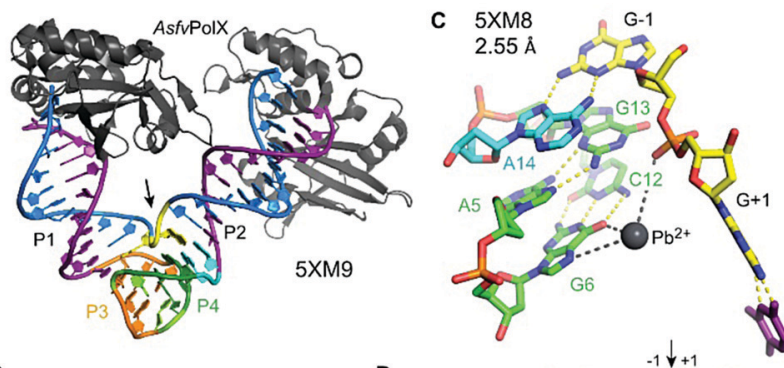

B

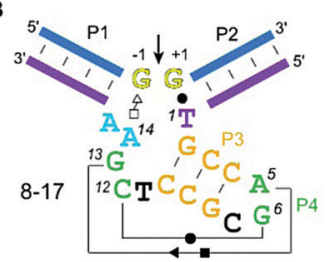

D

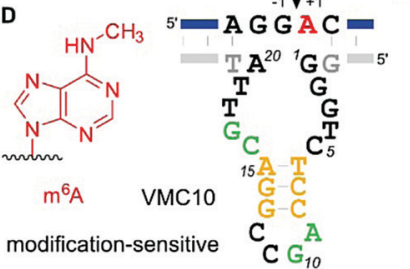
Fig. 13 8-17 and VMC10 DNAzymes. (A) Tertiary structure and
(B) secondary structure overview of RNA-cleaving 8-17 DNAzyme (crystallized with AsfvPolX protein, grey), GG kink at the cleavage site in yellow. (C) Excerpt of the catalytic core showing the G13 acting as a base for deprotonation of $2^{\prime}-\mathrm{OH}$ (missing in the structure) and $\mathrm{Pb}^{2+}$ coordinating to G6. (D) Secondary structure of $\mathrm{m}^{6} \mathrm{~A}$-sensitive VMC10 DNAzyme. ${ }^{240}$ Features suggested to resemble similar functions compared to 8-17 are shown in matching colors to (B).

catalysis was also established by (bio)chemical atomic mutagenesis data, ${ }^{238}$ and analysed in detail in combination with molecular dynamics (MD) simulations. ${ }^{241,242}$ Such investigations may reveal the degree of shared mechanistic features between artificial RNA-cleaving DNA catalysts and naturally evolved ribozyme counterparts. However, the MD simulations were carried out with $\mathrm{Pb}^{2+}$, and it is currently unclear if the results are transferable to the more biologically relevant $\mathrm{Mg}^{2+}$. This question is of special interest, since FRET analyses revealed different folding landscapes with different metal ions. $^{243,244}$ Thus, future structures of the 8-17 DNAzyme in complex with an RNA substrate strand carrying a $2^{\prime}$-OMe or $2^{\prime}$-F modified nucleotide at the cleavage site, and in the presence of $\mathrm{Mg}^{2+}$ are highly desirable. Along the same lines, it will be interesting to study the structural features of $\mathrm{Na}^{+}$-specific DNAzymes, for which a single point mutation has recently been described to result in switching the catalytic mechanism from general base to general acid catalysis. ${ }^{245}$

RNA modification-sensitive DNAzymes. Recently, RNA-cleaving deoxyribozymes were evolved to recognize chemical nucleobase modifications on the RNA substrate. Such DNAzymes may become beneficial tools for epitranscriptomic research for the validation of distinct sites of posttranscriptional modifications. ${ }^{240,246,247}$ Moreover, they can become defining components in screening assays for activators or inhibitors of writer or eraser enzymes.

The 2'-O-methylation of rRNA was the first posttranscriptional RNA modification studied by RNA-cleaving deoxyribozymes. ${ }^{246}$ For mechanistic reasons, methylation at the cleavage site inhibits the DNA enzyme, and the methylated RNA remains intact. In contrast, nucleobase modifications 5-methylcytidine $\left(\mathrm{m}^{5} \mathrm{C}\right)$, 5-methyluridine $\left(\mathrm{m}_{5} \mathrm{U}\right)$, and pseudouridine $(\psi)$ in tRNA did not interfere with DNA-catalysed RNA cleavage. Both modifications barely influenced cleavage rate and yield of 10-23 DNAzymes, and were detected at the $5^{\prime}$-terminus of the downstream fragment by TLC and LC-MS methods. ${ }^{247,248}$ However, 10-23 is limited to cleaving purine|pyrimidine $(\mathrm{R} \mid \mathrm{Y})$ junctions, and thus is not useful for the analysis of modified purine nucleotides. Selective DNA enzymes that result in distinct cleavage events for modified RNA and unmodified RNA would simplify the analysis. The first RNA-cleaving DNA enzyme that showed accelerated cleavage of modified RNA was shown to distinguish $N^{6}$-methyladenosine $\left(\mathrm{m}^{6} \mathrm{~A}\right)$ from unmodified adenosine at the cleavage site. ${ }^{240}$ Surprisingly, better selectivity was obtained in the opposite direction, i.e. it was easier to find DNA enzymes that are strongly inhibited by $\mathrm{m}^{6} \mathrm{~A}$. The VMC10 DNA enzyme (Fig. 13D) efficiently cleaved unmodified RNA and left methylated RNA intact. Such enzymes are useful for the enrichment of sparsely methylated RNA, and can be used to validate predicted $\mathrm{m}^{6} \mathrm{~A}$ sites in isolated cellular RNA. ${ }^{145,249}$

Besides the development of tools for epitranscriptomic research, it is of fundamental interest to understand if and how DNA enzymes distinguish different methylation/ modification states of the target RNA. In the absence of any crystal structure, the responsible supramolecular contacts remain speculative. While $\mathrm{m}^{6} \mathrm{~A}$-specific reader proteins recognize $\mathrm{m}^{6} \mathrm{~A}$ via a methyl $-\pi$ interaction with heteroaromatic amino acid side chains (such as the tryptophan cage in YTH proteins), ${ }^{250}$ no analogous interactions are known in RNA/DNA-only structures. However, preferred structural motifs are known in RNA, in which $\mathrm{m}^{6} \mathrm{~A}$ together with $\mathrm{Mg}^{2+}$ has a stabilizing effect, ${ }^{251}$ and others in which $\mathrm{m}^{6} \mathrm{~A}$ modulates base-pairing patterns, ${ }^{252-254}$ or RNA annealing kinetics. ${ }^{255}$ In the DNA active site of VMC10, it is thus conceivable, that the methyl group of $\mathrm{m}^{6} \mathrm{~A}$ interferes with an essential $\mathrm{H}$-bonding interaction within the core of the deoxyribozyme and thus inhibits catalytic activity. Interestingly, the predicted VMC10 secondary structure shares features reminiscent of 8-17 (Fig. 13). However, no interference of $\mathrm{m}^{6} \mathrm{~A}$ can be predicted from the orientation of the nucleotides around the cleavage site. ${ }^{237}$ Likely, additional contacts are formed between the RNA substrate and the guanine-rich bulge between the predicted $\mathrm{P} 2$ and $\mathrm{P} 3$ stems.

Compared to $\mathrm{m}^{6} \mathrm{~A}$, much stronger activating effects on DNA enzymes were found with a larger nucleobase modification, $N^{6}$-isopentenyl adenosine $\left(i^{6} \mathrm{~A}\right) .{ }^{256}$ The prenylated adenosine is a natural tRNA modification that is conserved in certain tRNAs in bacteria and eukaryotes, ${ }^{257}$ and the hydrophobic nature of $\mathrm{i}^{6} \mathrm{~A}$ was suggested to facilitate its association to membranes. ${ }^{258}$ It remains to be determined which type of non-covalent interactions are most influential to explain the pronounced preference of 2500-fold faster cleavage of $\mathrm{i}^{6} \mathrm{~A}$ RNA compared to unmodified RNA. ${ }^{256}$

The findings on $\mathrm{m}^{6} \mathrm{~A}$ and $\mathrm{i}^{6} \mathrm{~A}$-selective DNAzymes spur further interest in the development of DNA catalysts targeting other RNA modifications. For example, it would be quite spectacular to evolve DNAzymes that can discriminate the three natural singly methylated cytidine isomers $\mathrm{m}^{3} \mathrm{C}, \mathrm{m}^{4} \mathrm{C}$ and $\mathrm{m}^{5} \mathrm{C}$ from unmodified cytidine. Ideally, individual DNAzymes should selectively cleave only one out of the four targets. Since 
none of the previously reported 8-17 analogues is particularly good at cleaving $\mathrm{N} / \mathrm{C}$ junctions in all-RNA substrates, ${ }^{232,259}$ advanced in vitro evolution strategies need to be developed to overcome the tyranny of the 8-17 motif. ${ }^{236}$ Deep sequencing analyses of enriched selection libraries with in situ analyses of cleavage activity and selectivity ${ }^{26,260}$ may lead to the identification of new catalytic DNA motifs for the site-specific interrogation of difficult-to-cleave RNA substrates and isomers of posttranscriptional RNA modifications.

\section{DNA-cleaving DNA enzymes}

In contrast to RNA transesterification, the site-specific cleavage of DNA is more challenging to achieve, because the internal nucleophile for attack at the scissile phosphate is missing. Several different cleavage mechanism were employed by DNA-cleaving DNA enzymes, including $\mathrm{Cu}^{2+}$-mediated oxidative cleavage, and strand breaks at apurinic sites after DNA-catalysed deglycosylation. ${ }^{261}$ A serendipitous discovery of a bimetallic deoxyribozyme that required $\mathrm{Zn}^{2+}$ and $\mathrm{Mn}^{2+}$ for hydrolytic phosphodiester cleavage activity, generated well-defined DNA fragments with impressive rate enhancements and multiple turnover. ${ }^{262}$ Further selections in the presence of different metals produced DNA-cleaving sequences that required only $\mathrm{Zn}^{2+},{ }^{263}$ or were reactive with low concentrations of lanthanides. ${ }^{264}$ An elegant selection strategy involving circular DNA revealed generally applicable $\mathrm{Zn}^{2+}$-dependent DNA-cleaving DNAzymes, ${ }^{265,266}$ that were engineered for mass production of DNA origami. ${ }^{267}$ Deoxyribozyme pairs were constructed into self-cleaving cassettes that enabled the generation of all necessary single strands for several DNA origami structures from large-scale bacteriophage cultures.

\section{Nucleic acid-catalysed formation of phosphodiester bonds in RNA}

Formally, the reverse of phosphodiester cleavage, is the formation of a new $3^{\prime}-5^{\prime}$ linkage between two RNA fragments. This connection can be furnished by different mechanisms. The microscopic reversibility of the cleavage by transesterification, initiated by the 2 '-OH attack on the scissile phosphodiester, suggests that regioselective opening of the cyclic phosphate by attack from the $5^{\prime}-\mathrm{OH}$ results in regiospecific ligation. In the laboratory, this reaction is employed by the twin ribozyme for RNA labelling and mutagenesis. ${ }^{268}$ The twin ribozyme is an engineered version of the hairpin ribozyme found in the satellite RNA of tobacco ringspot virus, and thus it is a variant of the small nucleolytic ribozymes described above.

In contrast to opening of $2^{\prime}, 3^{\prime}$-cyclophosphates, an alternative practically useful ligation reaction involves the $3^{\prime}-\mathrm{OH}$ as the nucleophile and an activated $5^{\prime}$-phosphate as the electrophile. Most commonly, $5^{\prime}$-triphosphates are used, but $5^{\prime}$-adenylates, nicotinamides, or substituted $5^{\prime}$-phosphorimidazolides have also been employed. ${ }^{269-271}$ Fundamentally, this reaction resembles the elongation step catalysed by RNA polymerases, and is thus also of great interest in the context of origin of life research and the RNA world, in which an RNA polymerase ribozyme would have been able to copy functional RNA molecules. ${ }^{118,272}$

\section{RNA-ligating ribozymes \& polymerase ribozymes}

In contrast to the detailed knowledge available on RNA/DNAcatalysed RNA cleavage reactions summarized above, very little is known on structures and mechanisms of RNA ligase and RNA polymerase ribozymes. The crystal structures for two types of RNA ligases were reported between 2007 and $2011,{ }^{273-275}$ but since then no additional structures have become available of any other ligase or polymerase ribozymes.

The class I ligase ${ }^{276}$ and the L1 ligase ${ }^{277}$ share the arrangement of the ligation substrates in a discontinuous double helix, firmly hybridized to a complementary template strand (Fig. 14). An engineered version of the class I ligase is still the fastest ribozyme described today with a $k_{\text {cat }}$ of $100 \mathrm{~min}^{-1} \cdot{ }^{274}$ The crystal structures of the pre- and post-catalytic states reveal complex catalytic strategies. In the pre-catalytic state of the class I ligase, the $5^{\prime}$-triphosphate takes an unexpected orientation in the major groove of the primer-template duplex. ${ }^{273}$ The 3 '-OH nucleophile is positioned for in-line attack with the help of a $\mathrm{Mg}^{2+}$ ion, and interactions with nucleobase and ribose functional groups also play important roles. ${ }^{273}$

Structural analogues of the L1 ligase, were derived from independent selections, originally in the absence of cytidine (R3 ligase), and then re-selected with all four nucleotides (R3C ligase) and further evolved for enhanced catalytic efficiencies (F1 ligase). ${ }^{278,279}$ Recently, large-scale mutagenesis and the evaluation of more than 10000 sequence variants resulted in the systematic minimization of the catalytic core to 18 nucleotides (minF1). ${ }^{280}$ The class I and R3C ligases were the starting points for the evolution of RNA polymerase ribozymes, and their evolutionary history was recently summarized. ${ }^{272}$ Some of the most exciting and creative strategies towards the synthesis of long more complex RNAs involved the evolution in ice, ${ }^{281}$ the evolution of a cross-chiral RNA ligase ribozyme, ${ }^{282}$ and the templated polymerization of RNA trinucleotide triphosphates (triplet building blocks). ${ }^{283}$ A highly optimized ribozyme was able to synthesize DNA polymers on an RNA template. ${ }^{284}$ The most recent ribozyme generation was shown to synthesise its own evolutionary ancestor in three pieces, which selfassembled into an active class I RNA ligase. ${ }^{285}$

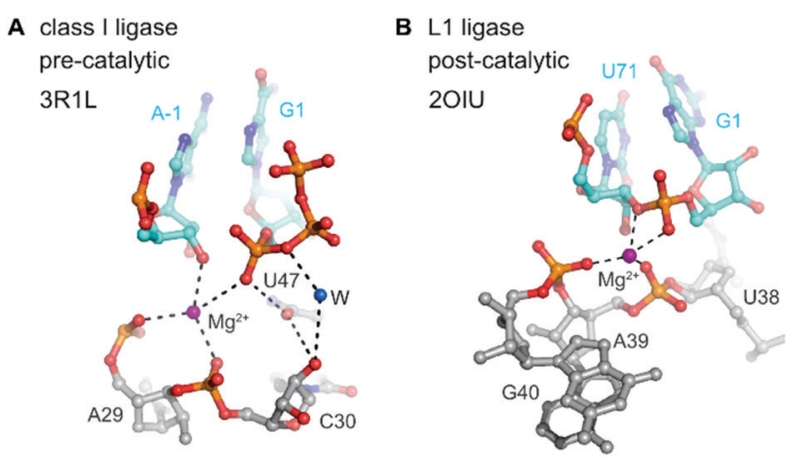

Fig. 14 Class I ligase and L1 ligase ribozymes. Positioning of the reactive nucleotides in the active centre of class I ligase $274(A)$ and L1 ligase (B) $^{275}$ (B) ribozymes. Nucleotides at ligation junction are coloured in cyan, and preand postcatalytic structures are compared. 


\section{RNA-ligation catalysed by DNA (deoxyribozymes)}

The generally useful RNA ligase deoxyribozyme named 9DB1 was reported by Silverman in $2005 .^{286}$ It was derived from an in vitro selection experiment, in which a selection pressure demanded the regioselective formation of only $3^{\prime}, 5^{\prime}$ linkages. ${ }^{286}$ The crystal structure of 9DB1 was reported in 2016 as the first three-dimensional structure of a DNA enzyme in a catalytically relevant conformation. ${ }^{287}$ The structure provided unprecedented insights into the architecture of an active site made of DNA. The 9DB1 DNA complexed with its RNA ligation product forms a double pseudoknot in which two thymidine loop nucleotides interact with the A-G RNA nucleotides directly at the ligation junction (Fig. 15). These interactions could not be predicted from the available biochemical data. ${ }^{288-290}$ The insights from the crystal structure enabled engineering of the deoxyribozyme to broaden the substrate scope of RNA ligation.

The crystal structure revealed a static picture of the postcatalytic product-bound state of the DNA enzyme and was unable to explain the involvement of magnesium ions as cofactors for accelerating RNA ligation. An internucleotide phosphodiester oxygen was suggested to make a critical contact, ${ }^{287}$ and this was supported by computational analyses and molecular dynamics simulations that revealed a plateau in the energy landscape, suggesting a concerted asynchronous transition state. ${ }^{291}$ The concerted phosphoryl and proton transfer pathway was found to be endergonic, and the release

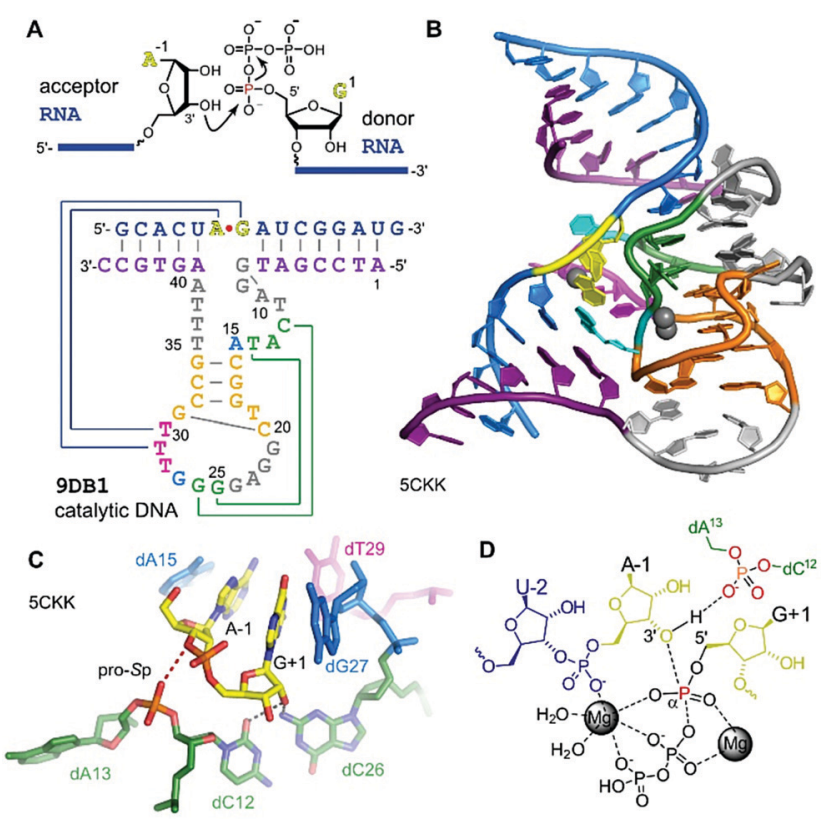

Fig. 15 9DB1 DNAzyme. (A) Reaction catalysed by 9DB1 RNA ligase deoxyribozyme and secondary structure of DNA enzyme in complex with ligated RNA product. (B) Global architecture of the DNA catalyst. (C) Active site of 9DB1. The ligation junction, the base-pairing (magenta) and stacking (blue) nucleotides, the putatively catalytic dA13 phosphate, oriented by the long-range base pair (green) brings the pro-Sp non bridging oxygen in proximity to the $3^{\prime}$-oxygen of $A-1$. (D) Schematic illustration of the transition state model from $Q M / M M{ }^{291}$ suggesting a concerted phosphoryl and proton transfer involving the coordination of two metal ions. of the protonated pyrophosphate in complex with $\mathrm{Mg}^{2+}$ ions was suggested to drive the reaction towards ligation. The direct protonation of the phosphate needs further experimental confirmation, since slight rearrangements in the active site could support an alternative explanation, as recently suggested by density functional theory (DFT) calculations of an alternative active-site model of 9DB1. ${ }^{292}$ However, this earlier model did not consider the involvement of metal ions, which are required for catalysis. ${ }^{286,290}$

On the other hand, the proposed contacts of the metal ions in the active site with the triphosphate and RNA substrate were experimentally validated by phosphorothioate substitution and analysis of reaction rates. ${ }^{291}$ Nevertheless, structural models in the pre-catalytic state with bound metal ions and the pyrophosphate leaving group, with a transition state analogue or with an $\alpha, \beta$-non-hydrolysable triphosphate analogue are highly desired. The structure revealed a broader range of sugarphosphate backbone conformations in the DNA core than in natural and synthetic ribozymes. ${ }^{287}$ This suggests that the missing of the 2'-OH groups of DNA expands the conformational flexibility of DNA relative to RNA, to allow additional modes of interaction. This concept is likely to be employed by other deoxyribozymes, for which the structure is not yet known.

\section{(Deoxy)ribozymes for covalent RNA labelling}

RNA-ligating ribozymes and deoxyribozymes can not only activate the 3 '-terminal hydroxy group, but the active site can be directed to a specific internal nucleotide and activate the $2^{\prime}$-OH for nucleophilic attack on a triphosphate, resulting in the formation of $2^{\prime}, 5^{\prime}$-branched RNA. ${ }^{293}$ Surprisingly, such branching reactions were identified when in vitro selections for RNA-ligating deoxyribozymes were carried out in the absence of a selection pressure for formation of the linear native connection. ${ }^{294}$ These unexpected DNA enzymes were turned into useful tools for generating artificial lariat RNAs (that contained the native linkage at the branch site), ${ }^{295-297}$ and for the attachment of oligonucleotides that modulated the folding and function of larger RNAs and ribozymes. ${ }^{298,299}$ Moreover, the branch-forming deoxyribozyme 10DM24 was engineered for RNA labelling. ${ }^{300,301}$ Together with the finding, that the ligation reaction was significantly accelerated by lanthanide ions $\left(\right.$ e.g. $\left.\mathrm{Tb}^{3+}\right),{ }^{302}$ fast and efficient RNA labelling was achieved by the attachment of functionalized or fluorescently labelled guanines via the $2^{\prime}, 5^{\prime}$-branched linkage. ${ }^{303}$ Sine lanthanide ions cannot completely replace divalent $\mathrm{Mg}^{2+}$ or $\mathrm{Mn}^{2+}$, they are more likely to play a supporting structural role rather than being directly involved in the catalytic mechanism.

The rather complex metal ion requirements of 10DM24 may be overcome by alternative nucleic acid catalysts. In this respect, ribozymes for a comparable labelling strategy of RNA were recently described. ${ }^{304,305}$ These RNA catalysts resulted from a targeted in vitro selection strategy that used a structured RNA library to guide the ribozyme to the predetermined labelling site, and were directly selected with ATP derivatives as small-molecule labelling reagents. ${ }^{305}$ To enhance the bioorthogonality of this RNA labelling strategy, a new generation of 


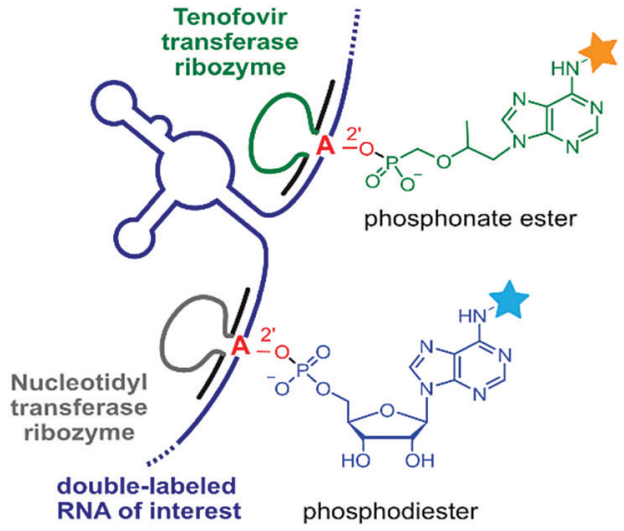

Fig. 16 RNA-catalysed RNA labelling reactions produce 2'-linked phosphodiester or phosphonate esters with fluorescent nucleotide analogues as substrates. Orthogonal ribozymes allow site-specific dual labelling of RNA. ${ }^{304,305}$

ribozymes was developed that used antiviral nucleotide analogues as substrates. ${ }^{304}$ In particular, tenofovir-transferase ribozymes were obtained that are orthogonal to the adenylyltransferase ribozymes, and generate a branched phosphonate linkage instead of the phosphate linkage (Fig. 16). Site-specific installation of FRET reporters was demonstrated on small and large RNAs (5S, $16 \mathrm{~S}$ and 23S rRNA) in the context of total cellular RNA. ${ }^{304,305}$ These studies pave the way for future evolution of catalytic RNA labelling tools in cells.

\section{Outlook on further fundamental studies on ribozymes and deoxyribozymes}

Besides important insights into the mechanism of ribozymes and DNAzymes that are anticipated from chemical and biophysical studies, as well as from crystal structures of ribozymes/ DNAzymes (pre- and post-catalytic states, transition state analogues), exploring their conformational dynamics by modern single molecule FRET and NMR spectroscopic methods would contribute to a deeper understanding of their catalytic activity. The expected micro- to milliseconds timescale of nucleoside dynamics in the active site, and of nucleosides at tertiary interactions should be accessible by using selective ${ }^{13} \mathrm{C}$ labelling patterns and relaxation dispersion NMR experiments. ${ }^{306-310}$ In this way, populations of nucleoside conformations (concerning e.g. ribose pucker, glycosidic bond angles, etc.) that are crucial for approaching the transition state of phosphodiester cleavage could be revealed. Finally, using selective ${ }^{15} \mathrm{~N}$ labelling patterns, nucleobase tautomers and/or ionic forms potentially involved in catalysis could be made visible and this would represent a first direct spectroscopic verification in ribozymes/DNAzymes.

Additional exciting future directions target the evolution of nucleic acid catalysts for reactions not yet known to be catalysed by RNA and DNA. A particular challenge is to find ribozymes and deoxyribozymes that modulate the modification state of RNA, directly by installing RNA modifications or by removing them, rather than degrading modified RNA or the unmodified counterpart. Fundamental research will then advance nucleic acid enzymes beyond analytical tools, and will allow entrance to the synthetic biology regime as an active modulator.

\section{Summary}

This review summarised common versus distinct structural and functional strategies that are applied by fluorogen-activating RNA aptamers, recently discovered bacterial riboswitches, and ribozymes/DNAzymes that catalyse phosphodiester chemistry. Fundamental studies on their structure and folding, their dynamics and reactivity, and their modification and labelling are continuously performed because the understanding of nucleic acids inherent molecular properties is needed to harness these modules for advanced applications in biotechnology and biomedicine.

\section{Conflicts of interest}

There are no conflicts to declare.

\section{Acknowledgements}

We thank Olga Krasheninina (Innsbruck) and Christian Steinmetzger (Würzburg) for critical reading of the manuscript. We thank all members of the Micura and Höbartner groups for their enthusiasm in making our projects happen and for valuable discussions during the course of writing this review. This work was supported by the Austrian Science Fund FWF (P27947, P31691, F8011-B), the Austrian Research Promotion Agency FFG [West Austrian BioNMR 858017], and the Wiener Wissenschafts-, Forschungs- und Technologiefonds (WWTF LS17-003), the German Science Foundation DFG (SPP 1784) and the European Research Council [ERC consolidator grant 682586 to C. H.].

\section{Notes and references}

1 Z. Miao and E. Westhof, Annu. Rev. Biophys., 2017, 46, 483-503.

2 D. J. Patel, Cold Spring Harbor Perspect. Biol., 2016, 8, a018754.

3 R. J. Trachman and A. R. Ferre-D'Amare, Q. Rev. Biophys., 2019, 52, e8.

4 A. Roth and R. R. Breaker, Annu. Rev. Biochem., 2009, 78, 305-334.

5 R. Micura and C. Höbartner, ChemBioChem, 2003, 4, 984-990.

6 B. Fürtig, S. Nozinovic, A. Reining and H. Schwalbe, Curr. Opin. Struct. Biol., 2015, 30, 112-124.

7 S. Ray, J. R. Widom and N. G. Walter, Chem. Rev., 2018, 118, 4120-4155.

8 M. F. Juette, D. S. Terry, M. R. Wasserman, Z. Zhou, R. B. Altman, Q. Zheng and S. C. Blanchard, Curr. Opin. Chem. Biol., 2014, 20, 103-111.

9 L. R. Ganser, M. L. Kelly, D. Herschlag and H. M. Al-Hashimi, Nat. Rev. Mol. Cell Biol., 2019, 20, 474-489. 
10 A. V. Bedard, E. D. M. Hien and D. A. Lafontaine, Biochim. Biophys. Acta, Gene Regul. Mech., 2020, 1863, 194501.

11 A. I. Taylor, G. Houlihan and P. Holliger, Cold Spring Harbor Perspect. Biol., 2019, 11, a032490.

12 D. Gillingham, S. Geigle and O. Anatole von Lilienfeld, Chem. Soc. Rev., 2016, 45, 2637-2655.

13 D. Balke, R. Hieronymus and S. Müller, Adv. Biochem. Eng./ Biotechnol., 2020, 170, 21-35.

14 Y. Yokobayashi, Curr. Opin. Chem. Biol., 2019, 52, 72-78.

15 S. Tsukiji, S. B. Pattnaik and H. Suga, Nat. Struct. Biol., 2003, 10, 713-717.

16 P. Cernak and D. Sen, Nat. Chem., 2013, 5, 971-977.

17 N. Muthmann, K. Hartstock and A. Rentmeister, Wiley Interdiscip. Rev.: RNA, 2020, 11, e1561.

18 M. Neveu, H. J. Kim and S. A. Benner, Astrobiology, 2013, 13, 391-403.

19 S. K. Wolk, W. S. Mayfield, A. D. Gelinas, D. Astling, J. Guillot, E. N. Brody, N. Janjic and L. Gold, Proc. Natl. Acad. Sci. U. S. A., 2020, 117, 8236-8242.

20 A. D. Ellington and J. W. Szostak, Nature, 1990, 346, 818-822.

21 C. Tuerk and L. Gold, Science, 1990, 249, 505-510.

22 S. Breuers, L. L. Bryant, T. Legen and G. Mayer, Methods, 2019, 161, 3-9.

23 M. R. Gotrik, T. A. Feagin, A. T. Csordas, M. A. Nakamoto and H. T. Soh, Acc. Chem. Res., 2016, 49, 1903-1910.

24 K. H. Cole and A. Luptak, Methods Enzymol., 2019, 621, 329-346.

25 R. Nutiu, R. C. Friedman, S. Luo, I. Khrebtukova, D. Silva, R. Li, L. Zhang, G. P. Schroth and C. B. Burge, Nat. Biotechnol., 2011, 29, 659-664.

26 A. D. Pressman, Z. Liu, E. Janzen, C. Blanco, U. F. Müller, G. F. Joyce, R. Pascal and I. A. Chen, J. Am. Chem. Soc., 2019, 141, 6213-6223.

27 Z. Chen, R. D. Kibler, A. Hunt, F. Busch, J. Pearl, M. Jia, Z. L. VanAernum, B. I. M. Wicky, G. Dods, H. Liao, M. S. Wilken, C. Ciarlo, S. Green, H. El-Samad, J. Stamatoyannopoulos, V. H. Wysocki, M. C. Jewett, S. E. Boyken and D. Baker, Science, 2020, 368, 78-84.

28 J. B. Siegel, A. Zanghellini, H. M. Lovick, G. Kiss, A. R. Lambert, J. L. St. Clair, J. L. Gallaher, D. Hilvert, M. H. Gelb, B. L. Stoddard, K. N. Houk, F. E. Michael and D. Baker, Science, 2010, 329, 309-313.

29 E. Marcos, B. Basanta, T. M. Chidyausiku, Y. Tang, G. Oberdorfer, G. Liu, G. V. Swapna, R. Guan, D. A. Silva, J. Dou, J. H. Pereira, R. Xiao, B. Sankaran, P. H. Zwart, G. T. Montelione and D. Baker, Science, 2017, 355, 201-206.

30 F. Lapenta, J. Aupic, Z. Strmsek and R. Jerala, Chem. Soc. Rev., 2018, 47, 3530-3542.

31 J. D. Yesselman, D. Eiler, E. D. Carlson, M. R. Gotrik, A. E. d'Aquino, A. N. Ooms, W. Kladwang, P. D. Carlson, X. Shi, D. A. Costantino, D. Herschlag, J. B. Lucks, M. C. Jewett, J. S. Kieft and R. Das, Nat. Nanotechnol., 2019, 14, 866-873.

32 M. J. Wu, J. O. L. Andreasson, W. Kladwang, W. Greenleaf and R. Das, ACS Synth. Biol., 2019, 8, 1838-1846.
33 L. A. Holeman, S. L. Robinson, J. W. Szostak and C. Wilson, Folding Des., 1998, 3, 423-431.

34 C. Baugh, D. Grate and C. Wilson, J. Mol. Biol., 2000, 301, 117-128.

35 J. R. Babendure, S. R. Adams and R. Y. Tsien, J. Am. Chem. Soc., 2003, 125, 14716-14717.

36 S. Neubacher and S. Hennig, Angew. Chem., Int. Ed., 2019, 58, 1266-1279.

37 F. Bouhedda, A. Autour and M. Ryckelynck, Int. J. Mol. Sci., 2018, 19, 44.

38 M. You and S. R. Jaffrey, Annu. Rev. Biophys., 2015, 44, 187-206.

39 Y. Xia, R. Zhang, Z. Wang, J. Tian and X. Chen, Chem. Soc. Rev., 2017, 46, 2824-2843.

40 J. S. Paige, K. Y. Wu and S. R. Jaffrey, Science, 2011, 333, 642-646.

41 G. S. Filonov, J. D. Moon, N. Svensen and S. R. Jaffrey, J. Am. Chem. Soc., 2014, 136, 16299-16308.

42 K. D. Warner, M. C. Chen, W. Song, R. L. Strack, A. Thorn, S. R. Jaffrey and A. R. Ferre-D'Amare, Nat. Struct. Mol. Biol., 2014, 21, 658-663.

43 H. Huang, N. B. Suslov, N. S. Li, S. A. Shelke, M. E. Evans, Y. Koldobskaya, P. A. Rice and J. A. Piccirilli, Nat. Chem. Biol., 2014, 10, 686-691.

44 G. S. Filonov, W. Song and S. R. Jaffrey, Biochemistry, 2019, 58, 1560-1564.

45 E. A. Ageely, Z. J. Kartje, K. J. Rohilla, C. L. Barkau and K. T. Gagnon, ACS Chem. Biol., 2016, 11, 2398-2406.

46 J. C. Savage, M. A. Davare and U. Shinde, Chem. Commun., 2020, 56, 2634-2637.

47 A. Autour, E. Westhof and M. Ryckelynck, Nucleic Acids Res., 2016, 44, 2491-2500.

48 P. Fernandez-Millan, A. Autour, E. Ennifar, E. Westhof and M. Ryckelynck, $R N A, 2017,23,1788-1795$.

49 W. Song, G. S. Filonov, H. Kim, M. Hirsch, X. Li, J. D. Moon and S. R. Jaffrey, Nat. Chem. Biol., 2017, 13, 1187-1194.

50 K. D. Warner, L. Sjekloca, W. Song, G. S. Filonov, S. R. Jaffrey and A. R. Ferre-D'Amare, Nat. Chem. Biol., 2017, 13, 1195-1201.

51 L. Sjekloca and A. R. Ferre-D'Amare, Cell Chem. Biol., 2019, 26, 1159-1168. e1154.

52 C. Steinmetzger, N. Palanisamy, K. R. Gore and C. Höbartner, Chem. - Eur. J., 2019, 25, 1931-1935.

53 C. Steinmetzger, I. Bessi, A. K. Lenz and C. Höbartner, Nucleic Acids Res., 2019, 47, 11538-11550.

54 C. Steinmetzger, C. Bäuerlein and C. Höbartner, Angew. Chem., Int. Ed., 2020, 59, 6760-6764.

55 D. M. Shcherbakova, M. A. Hink, L. Joosen, T. W. Gadella and V. V. Verkhusha, J. Am. Chem. Soc., 2012, 134, 7913-7923.

56 E. V. Dolgosheina, S. C. Jeng, S. S. Panchapakesan, R. Cojocaru, P. S. Chen, P. D. Wilson, N. Hawkins, P. A. Wiggins and P. J. Unrau, ACS Chem. Biol., 2014, 9, 2412-2420.

57 A. Autour, S. C. Y. Jeng, A. D. Cawte, A. Abdolahzadeh, A. Galli, S. S. S. Panchapakesan, D. Rueda, M. Ryckelynck and P. J. Unrau, Nat. Commun., 2018, 9, 656. 
58 R. J. Trachman, 3rd, A. Autour, S. C. Y. Jeng, A. Abdolahzadeh, A. Andreoni, R. Cojocaru, R. Garipov, E. V. Dolgosheina, J. R. Knutson, M. Ryckelynck, P. J. Unrau and A. R. FerreD'Amare, Nat. Chem. Biol., 2019, 15, 472-479.

59 R. J. Trachman, 3rd, A. Abdolahzadeh, A. Andreoni, R. Cojocaru, J. R. Knutson, M. Ryckelynck, P. J. Unrau and A. R. Ferre-D'Amare, Biochemistry, 2018, 57, 3544-3548.

60 R. J. Trachman, 3rd, R. Cojocaru, D. Wu, G. Piszczek, M. Ryckelynck, P. J. Unrau and A. R. Ferre-D'Amare, Structure, 2020, 28, 776-785.

61 R. J. Trachman, 3rd, N. A. Demeshkina, M. W. L. Lau, S. S. S. Panchapakesan, S. C. Y. Jeng, P. J. Unrau and A. R. Ferre-D'Amare, Nat. Chem. Biol., 2017, 13, 807-813.

62 R. J. Trachman, 3rd, J. R. Stagno, C. Conrad, C. P. Jones, P. Fischer, A. Meents, Y. X. Wang and A. R. Ferre-D'Amare, Acta Crystallogr., Sect. F: Struct. Biol. Commun., 2019, 75, 547-551.

63 X. Tan, T. P. Constantin, K. L. Sloane, A. S. Waggoner, M. P. Bruchez and B. A. Armitage, J. Am. Chem. Soc., 2017, 139, 9001-9009.

64 S. A. Shelke, Y. Shao, A. Laski, D. Koirala, B. P. Weissman, J. R. Fuller, X. Tan, T. P. Constantin, A. S. Waggoner, M. P. Bruchez, B. A. Armitage and J. A. Piccirilli, Nat. Commun., 2018, 9, 4542.

65 X. Chen, D. Zhang, N. Su, B. Bao, X. Xie, F. Zuo, L. Yang, H. Wang, L. Jiang, Q. Lin, M. Fang, N. Li, X. Hua, Z. Chen, C. Bao, J. Xu, W. Du, L. Zhang, Y. Zhao, L. Zhu, J. Loscalzo and Y. Yang, Nat. Biotechnol., 2019, 37, 1287-1293.

66 J. Wu, S. Zaccara, D. Khuperkar, H. Kim, M. E. Tanenbaum and S. R. Jaffrey, Nat. Methods, 2019, 16, 862-865.

67 R. Wirth, P. Gao, G. U. Nienhaus, M. Sunbul and A. Jäschke, J. Am. Chem. Soc., 2019, 141, 7562-7571.

68 B. A. Sparano and K. Koide, J. Am. Chem. Soc., 2007, 129, 4785-4794.

69 S. Sato, M. Watanabe, Y. Katsuda, A. Murata, D. O. Wang and M. Uesugi, Angew. Chem., Int. Ed., 2015, 54, 1855-1858.

70 A. Murata, S. Sato, Y. Kawazoe and M. Uesugi, Chem. Commun., 2011, 47, 4712-4714.

71 A. Arora, M. Sunbul and A. Jäschke, Nucleic Acids Res., 2015, 43, e144.

72 M. Sunbul and A. Jäschke, Nucleic Acids Res., 2018, 46, e110.

73 M. Sunbul and A. Jäschke, Angew. Chem., Int. Ed., 2013, 52, 13401-13404.

74 F. Bouhedda, K. T. Fam, M. Collot, A. Autour, S. Marzi, A. Klymchenko and M. Ryckelynck, Nat. Chem. Biol., 2020, 16, 69-76.

75 E. Braselmann, A. J. Wierzba, J. T. Polaski, M. Chrominski, Z. E. Holmes, S. T. Hung, D. Batan, J. R. Wheeler, R. Parker, R. Jimenez, D. Gryko, R. T. Batey and A. E. Palmer, Nat. Chem. Biol., 2018, 14, 964-971.

76 P. J. McCown, K. A. Corbino, S. Stav, M. E. Sherlock and R. R. Breaker, RNA, 2017, 23, 995-1011.

77 N. Pavlova, D. Kaloudas and R. Penchovsky, Gene, 2019, 708, 38-48.

78 A. Peselis, A. Gao and A. Serganov, Biochimie, 2015, 117, 100-109.
79 A. Serganov and D. J. Patel, Curr. Opin. Struct. Biol., 2012, 22, 279-286.

80 A. Serganov and D. J. Patel, Annu. Rev. Biophys., 2012, 41, 343-370.

81 A. Nahvi, N. Sudarsan, M. S. Ebert, X. Zou, K. L. Brown and R. R. Breaker, Chem. Biol., 2002, 9, 1043.

82 A. S. Mironov, I. Gusarov, R. Rafikov, L. E. Lopez, K. Shatalin, R. A. Kreneva, D. A. Perumov and E. Nudler, Cell, 2002, 111, 747-756.

83 W. Winkler, A. Nahvi and R. R. Breaker, Nature, 2002, 419, 952-956.

84 X. Nou and R. J. Kadner, Proc. Natl. Acad. Sci. U. S. A., 2000, 97, 7190-7195.

85 Z. F. Hallberg, Y. Su, R. Z. Kitto and M. C. Hammond, Annu. Rev. Biochem., 2017, 86, 515-539.

86 T. H. T. Chau, D. H. A. Mai, D. N. Pham, H. T. Q. Le and E. Y. Lee, Int. J. Mol. Sci., 2020, 21, 3192.

87 K. B. Arnvig, Biochem. Soc. Trans., 2019, 47, 1091-1099.

88 J. D. Munzar, A. Ng and D. Juncker, Chem. Soc. Rev., 2019, 48, 1390-1419.

89 R. Galizi and A. Jaramillo, Curr. Opin. Biotechnol., 2019, 55, 103-113.

90 T. S. Lotz and B. Suess, Microbiol. Spectrum, 2018, 6, RWR0025-2018.

91 D. Yu and R. R. Breaker, RNA, 2020, 26, 960-968.

92 S. N. Malkowski, T. C. J. Spencer and R. R. Breaker, RNA, 2019, 25, 1616-1627.

93 L. Huang, J. Wang and D. Lilley, RNA, 2020, 26, 878-887.

94 R. M. Atilho, G. Mirihana Arachchilage, E. B. Greenlee, K. M. Knecht and R. R. Breaker, eLife, 2019, 8, e45210.

95 M. E. Sherlock, N. Sudarsan, S. Stav and R. R. Breaker, eLife, 2018, 7, e33908.

96 J. W. Nelson, R. M. Atilho, M. E. Sherlock, R. B. Stockbridge and R. R. Breaker, Mol. Cell, 2017, 65, 220-230.

97 M. E. Sherlock, S. N. Malkowski and R. R. Breaker, Biochemistry, 2017, 56, 352-358.

98 M. E. Sherlock and R. R. Breaker, Biochemistry, 2017, 56, 359-363.

99 C. W. Reiss, Y. Xiong and S. A. Strobel, Structure, 2017, 25, 195-202.

100 R. A. Battaglia, I. R. Price and A. Ke, RNA, 2017, 23, 578-585.

101 L. Huang, J. Wang, T. J. Wilson and D. M. J. Lilley, Cell Chem. Biol., 2017, 24, 1407-1415. e1402.

102 R. A. Battaglia and A. Ke, Wiley Interdiscip. Rev.: RNA, 2018, e1482, DOI: 10.1002/wrna.1482.

103 M. E. Sherlock, N. Sudarsan and R. R. Breaker, Proc. Natl. Acad. Sci. U. S. A., 2018, 115, 6052-6057.

104 A. J. Knappenberger, C. W. Reiss and S. A. Strobel, eLife, 2018, 7, e36381.

105 A. Peselis and A. Serganov, Nat. Chem. Biol., 2018, 14, 887-894.

106 M. E. Sherlock, H. Sadeeshkumar and R. R. Breaker, Biochemistry, 2019, 58, 401-410.

107 P. L. Sazani, R. Larralde and J. W. Szostak, J. Am. Chem. Soc., 2004, 126, 8370-8371. 
108 A. C. Wolter, A. K. Weickhmann, A. H. Nasiri, K. Hantke, O. Ohlenschlager, C. H. Wunderlich, C. Kreutz, E. Duchardt-Ferner and J. Wöhnert, Angew. Chem., Int. Ed., 2017, 56, 401-404.

109 W. C. Winkler, A. Nahvi, N. Sudarsan, J. E. Barrick and R. R. Breaker, Nat. Struct. Biol., 2003, 10, 701-707.

110 R. T. Fuchs, F. J. Grundy and T. M. Henkin, Nat. Struct. Mol. Biol., 2006, 13, 226-233.

111 G. Mirihana Arachchilage, M. E. Sherlock, Z. Weinberg and R. R. Breaker, RNA Biol., 2018, 15, 371-378.

112 A. Sun, C. Gasser, F. Li, H. Chen, S. Mair, O. Krasheninina, R. Micura and A. Ren, Nat. Commun., 2019, 10, 5728.

113 X. Chen, G. Mirihana Arachchilage and R. R. Breaker, RNA, 2019, 25, 1091-1097.

114 T. D. Ames, D. A. Rodionov, Z. Weinberg and R. R. Breaker, Chem. Biol., 2010, 17, 681-685.

115 J. C. Cochrane and S. A. Strobel, RNA, 2008, 14, 993-1002.

116 A. Kirschning, Angew. Chem., Int. Ed., 2020, DOI: 10.1002/ anie.201914786.

117 W. C. Winkler, A. Nahvi, A. Roth, J. A. Collins and R. R. Breaker, Nature, 2004, 428, 281-286.

118 G. F. Joyce and J. W. Szostak, Cold Spring Harbor Perspect. Biol., 2018, 10, a034801.

119 C. Anastasi, F. F. Buchet, M. A. Crowe, A. L. Parkes, M. W. Powner, J. M. Smith and J. D. Sutherland, Chem. Biodiversity, 2007, 4, 721-739.

120 H. Okamura, A. Crisp, S. Hübner, S. Becker, P. Rovo and T. Carell, Angew. Chem., Int. Ed., 2019, 58, 18691-18696.

121 J. E. Hein and D. G. Blackmond, Acc. Chem. Res., 2012, 45, 2045-2054.

122 M. Bolli, R. Micura and A. Eschenmoser, Chem. Biol., 1997, 4, 309-320.

123 S. Ishida, N. Terasaka, T. Katoh and H. Suga, Nat. Chem. Biol., 2020, 16, 702-709.

124 J. W. Weaver and A. Serganov, Nat. Struct. Mol. Biol., 2019, 26, 1081-1083.

125 E. B. Porter, J. T. Polaski, M. M. Morck and R. T. Batey, Nat. Chem. Biol., 2017, 13, 295-301.

126 J. L. Vinkenborg, N. Karnowski and M. Famulok, Nat. Chem. Biol., 2011, 7, 519-527.

127 M. Famulok, J. S. Hartig and G. Mayer, Chem. Rev., 2007, 107, 3715-3743.

128 M. Spöring, M. Finke and J. S. Hartig, Curr. Opin. Biotechnol., 2019, 63, 34-40.

129 M. Wieland and J. S. Hartig, Angew. Chem., Int. Ed., 2008, 47, 2604-2607.

130 C. Berens, F. Groher and B. Suess, Biotechnol. J., 2015, 10, 246-257.

131 B. Strobel, M. Spöring, H. Klein, D. Blazevic, W. Rust, S. Sayols, J. S. Hartig and S. Kreuz, Nat. Commun., 2020, 11, 714.

132 C. Wilson and J. W. Szostak, Nature, 1995, 374, 777-782.

133 S. Ameta and A. Jäschke, Chem. Sci., 2013, 4, 957-964.

134 A. K. Sharma, J. J. Plant, A. E. Rangel, K. N. Meek, A. J. Anamisis, J. Hollien and J. M. Heemstra, ACS Chem. Biol., 2014, 9, 1680-1684.
135 R. I. McDonald, J. P. Guilinger, S. Mukherji, E. A. Curtis, W. I. Lee and D. R. Liu, Nat. Chem. Biol., 2014, 10, 1049-1054.

136 T. R. Cech, Science, 2000, 289, 878-879.

137 S. K. Silverman, Trends Biochem. Sci., 2016, 41, 595-609.

138 K. Schlosser and Y. Li, Chem. Biol., 2009, 16, 311-322.

139 M. Illangasekare, G. Sanchez, T. Nickles and M. Yarus, Science, 1995, 267, 643-647.

140 H. Murakami, H. Saito and H. Suga, Chem. Biol., 2003, 10, 655-662.

141 G. Sengle, A. Eisenführ, P. S. Arora, J. S. Nowick and M. Famulok, Chem. Biol., 2001, 8, 459-473.

142 B. Seelig and A. Jäschke, Chem. Biol., 1999, 6, 167-176.

143 M. Chandra and S. K. Silverman, J. Am. Chem. Soc., 2008, 130, 2936-2937.

144 L. L. Martin, P. J. Unrau and U. F. Müller, Life, 2015, 5, 247-268.

145 A. Serganov and D. J. Patel, Nat. Rev. Genet., 2007, 8, 776-790.

146 A. V. Kazantsev, A. A. Krivenko, D. J. Harrington, S. R. Holbrook, P. D. Adams and N. R. Pace, Proc. Natl. Acad. Sci. U. S. A., 2005, 102, 13392-13397.

147 J. M. Buzayan, W. L. Gerlach and G. Bruening, Nature, 1986, 323, 349-353.

148 M. J. Fedor, J. Mol. Biol., 2000, 297, 269-291.

149 P. B. Rupert and A. R. Ferre-D'Amare, Nature, 2001, 410, 780-786.

150 P. B. Rupert, A. P. Massey, S. T. Sigurdsson and A. R. FerreD’Amare, Science, 2002, 298, 1421-1424.

151 M. Martick, L. H. Horan, H. F. Noller and W. G. Scott, Nature, 2008, 454, 899-902.

152 A. Mir, J. Chen, K. Robinson, E. Lendy, J. Goodman, D. Neau and B. L. Golden, Biochemistry, 2015, 54, 6369-6381.

153 G. A. Prody, J. T. Bakos, J. M. Buzayan, I. R. Schneider and G. Bruening, Science, 1986, 231, 1577-1580.

154 M. Martick and W. G. Scott, Cell, 2006, 126, 309-320.

155 A. Mir and B. L. Golden, Biochemistry, 2016, 55, 633-636.

156 L. Sharmeen, M. Y. Kuo, G. Dinter-Gottlieb and J. Taylor, J. Virol., 1988, 62, 2674-2679.

157 A. R. Ferre-D’Amare, K. Zhou and J. A. Doudna, Nature, 1998, 395, 567-574.

158 A. Ke, K. Zhou, F. Ding, J. H. Cate and J. A. Doudna, Nature, 2004, 429, 201-205.

159 S. R. Das and J. A. Piccirilli, Nat. Chem. Biol., 2005, 1, 45-52.

160 D. J. Klein and A. R. Ferre-D'Amare, Science, 2006, 313, 1752-1756.

161 J. C. Cochrane, S. V. Lipchock and S. A. Strobel, Chem. Biol., 2007, 14, 97-105.

162 D. M. Lilley, $R N A, 2004,10,151-158$.

163 N. B. Suslov, S. DasGupta, H. Huang, J. R. Fuller, D. M. Lilley, P. A. Rice and J. A. Piccirilli, Nat. Chem. Biol., 2015, 11, 840-846.

164 A. Roth, Z. Weinberg, A. G. Chen, P. B. Kim, T. D. Ames and R. R. Breaker, Nat. Chem. Biol., 2014, 10, 56-60.

165 Z. Weinberg, P. B. Kim, T. H. Chen, S. Li, K. A. Harris, C. E. Lunse and R. R. Breaker, Nat. Chem. Biol., 2015, 11, 606-610. 
166 A. R. Ferre-D’Amare and W. G. Scott, Cold Spring Harbor Perspect. Biol., 2010, 2, a003574.

167 Z. Zhong and G. Chen, Nat. Chem. Biol., 2015, 11, 830-831.

168 R. M. Jimenez, J. A. Polanco and A. Luptak, Trends Biochem. Sci., 2015, 40, 648-661.

169 E. A. Doherty and J. A. Doudna, Annu. Rev. Biophys. Biomol. Struct., 2001, 30, 457-475.

170 J. A. Doudna and T. R. Cech, Nature, 2002, 418, 222-228.

171 E. Westhof, J. Mol. Recognit., 2007, 20, 1-3.

172 W. G. Scott, L. H. Horan and M. Martick, Prog. Mol. Biol. Transl. Sci., 2013, 120, 1-23.

173 V. Singh, B. I. Fedeles and J. M. Essigmann, RNA, 2015, 21, 1-13.

174 D. L. Kellerman, D. M. York, J. A. Piccirilli and M. E. Harris, Curr. Opin. Chem. Biol., 2014, 21, 96-102.

175 J. C. Cochrane and S. A. Strobel, Acc. Chem. Res., 2008, 41, 1027-1035.

176 M. J. Fedor and J. R. Williamson, Nat. Rev. Mol. Cell Biol., 2005, 6, 399-412.

177 G. M. Emilsson, S. Nakamura, A. Roth and R. R. Breaker, RNA, 2003, 9, 907-918.

178 G. A. Soukup and R. R. Breaker, $R N A, 1999$, 5, 1308-1325.

179 P. C. Bevilacqua, M. E. Harris, J. A. Piccirilli, C. Gaines, A. Ganguly, K. Kostenbader, S. Ekesan and D. M. York, ACS Chem. Biol., 2019, 14, 1068-1076.

180 R. R. Breaker, G. M. Emilsson, D. Lazarev, S. Nakamura, I. J. Puskarz, A. Roth and N. Sudarsan, RNA, 2003, 9, 949-957.

181 B. P. Weissman, N. S. Li, D. York, M. Harris and J. A. Piccirilli, Biochim. Biophys. Acta, 2015, 1854, 1737-1745.

182 A. M. Pyle, Science, 1993, 261, 709-714.

183 M. Yarus, FASEB J., 1993, 7, 31-39.

184 J. A. Doudna and J. R. Lorsch, Nat. Struct. Mol. Biol., 2005, 12, 395-402.

185 C. Gasser, J. Gebetsberger, M. Gebetsberger and R. Micura, Nucleic Acids Res., 2018, 46, 6983-6995.

186 Y. Liu, T. J. Wilson, S. A. McPhee and D. M. Lilley, Nat. Chem. Biol., 2014, 10, 739-744.

187 D. Eiler, J. Wang and T. A. Steitz, Proc. Natl. Acad. Sci. U. S. A., 2014, 111, 13028-13033.

188 A. Ren, M. Kosutic, K. R. Rajashankar, M. Frener, T. Santner, E. Westhof, R. Micura and D. J. Patel, Nat. Commun., 2014, 5, 5534.

189 M. Kosutic, S. Neuner, A. Ren, S. Flur, C. Wunderlich, E. Mairhofer, N. Vusurovic, J. Seikowski, K. Breuker, C. Höbartner, D. J. Patel, C. Kreutz and R. Micura, Angew. Chem., Int. Ed., 2015, 54, 15128-15133.

190 J. Gebetsberger and R. Micura, Wiley Interdiscip. Rev.: RNA, 2017, 8, e1402.

191 R. R. Breaker, ACS Chem. Biol., 2017, 12, 886-891.

192 A. Ren, R. Micura and D. J. Patel, Curr. Opin. Chem. Biol., 2017, 41, 71-83.

193 T. J. Wilson, Y. Liu, C. Domnick, S. Kath-Schorr and D. M. Lilley, J. Am. Chem. Soc., 2016, 138, 6151-6162.

194 E. Fuchs, C. Falschlunger, R. Micura and K. Breuker, Nucleic Acids Res., 2019, 47, 7223-7234.
195 K. J. Messina and P. C. Bevilacqua, J. Am. Chem. Soc., 2018, 140, 10578-10582.

196 K. J. Messina, R. Kierzek, M. A. Tracey and P. C. Bevilacqua, Biochemistry, 2019, 58, 4857-4868.

197 N. Vusurovic, R. B. Altman, D. S. Terry, R. Micura and S. C. Blanchard, J. Am. Chem. Soc., 2017, 139, 8186-8193.

198 C. S. Gaines and D. M. York, J. Am. Chem. Soc., 2016, 138, 3058-3065.

199 M. N. Ucisik, P. C. Bevilacqua and S. Hammes-Schiffer, Biochemistry, 2016, 55, 3834-3846.

200 C. S. Gaines, T. J. Giese and D. M. York, ACS Catal., 2019, 9, 5803-5815.

201 A. A. Kognole and A. D. MacKerell, Jr., Biophys. J., 2020, 118, 1424-1437.

202 K. A. Harris, C. E. Lunse, S. Li, K. I. Brewer and R. R. Breaker, RNA, 2015, 21, 1852-1858.

203 A. Ren, N. Vusurovic, J. Gebetsberger, P. Gao, M. Juen, C. Kreutz, R. Micura and D. J. Patel, Nat. Chem. Biol., 2016, 12, 702-708.

204 L. A. Nguyen, J. Wang and T. A. Steitz, Proc. Natl. Acad. Sci. U. S. A., 2017, 114, 1021-1026.

205 S. Neuner, C. Falschlunger, E. Fuchs, M. Himmelstoss, A. Ren, D. J. Patel and R. Micura, Angew. Chem., Int. Ed., 2017, 56, 15954-15958.

206 M. Teplova, C. Falschlunger, O. Krasheninina, M. Egger, A. Ren, D. J. Patel and R. Micura, Angew. Chem., Int. Ed., 2020, 59, 2837-2843.

207 T. J. Wilson, Y. Liu, N. S. Li, Q. Dai, J. A. Piccirilli and D. M. J. Lilley, J. Am. Chem. Soc., 2019, 141, 7865-7875.

208 A. T. Torelli, J. Krucinska and J. E. Wedekind, RNA, 2007, 13, 1052-1070.

209 J. Han and J. M. Burke, Biochemistry, 2005, 44, 7864-7870.

210 L. Zheng, E. Mairhofer, M. Teplova, Y. Zhang, J. Ma, D. J. Patel, R. Micura and A. Ren, Nat. Commun., 2017, 8, 1180.

211 Y. Liu, T. J. Wilson and D. M. J. Lilley, Nat. Chem. Biol., 2017, 13, 508-513.

212 C. S. Gaines and D. M. York, Angew. Chem., Int. Ed., 2017, 56, 13392-13395.

213 N. Riccitelli and A. Luptak, Prog. Mol. Biol. Transl. Sci., 2013, 120, 123-171.

214 S. Li, C. E. Lünse, K. A. Harris and R. R. Breaker, $R N A, 2015$, 21, 1845-1851.

215 L. Zheng, C. Falschlunger, K. Huang, E. Mairhofer, S. Yuan, J. Wang, D. J. Patel, R. Micura and A. Ren, Proc. Natl. Acad. Sci. U. S. A., 2019, 116, 10783-10791.

216 J. H. Chen, R. Yajima, D. M. Chadalavada, E. Chase, P. C. Bevilacqua and B. L. Golden, Biochemistry, 2010, 49, 6508-6518.

217 B. L. Golden, Biochemistry, 2011, 50, 9424-9433.

218 B. Gong, J. H. Chen, P. C. Bevilacqua, B. L. Golden and P. R. Carey, Biochemistry, 2009, 48, 11961-11970.

219 P. Thaplyal, A. Ganguly, B. L. Golden, S. Hammes-Schiffer and P. C. Bevilacqua, Biochemistry, 2013, 52, 6499-6514.

220 G. J. Kapral, S. Jain, J. Noeske, J. A. Doudna, D. C. Richardson and J. S. Richardson, Nucleic Acids Res., 2014, 42, 12833-12846. 
221 R. R. Breaker and G. F. Joyce, Chem. Biol., 1994, 1, 223-229.

222 S. K. Silverman, Nucleic Acids Res., 2005, 33, 6151-6163.

223 G. F. Joyce, Annu. Rev. Biochem., 2004, 73, 791-836.

224 S. K. Silverman and D. A. Baum, Methods Enzymol., 2009, 469, 95-117.

225 A. A. Fokina, D. A. Stetsenko and J. C. Francois, Expert Opin. Biol. Ther., 2015, 15, 689-711.

226 L. Gong, Z. Zhao, Y. F. Lv, S. Y. Huan, T. Fu, X. B. Zhang, G. L. Shen and R. Q. Yu, Chem. Commun., 2015, 51, 979-995.

227 K. Hwang, Q. Mou, R. J. Lake, M. Xiong, B. Holland and Y. Lu, Inorg. Chem., 2019, 58, 13696-13708.

228 L. Ma and J. Liu, iScience, 2020, 23, 100815.

229 X. B. Zhang, R. M. Kong and Y. Lu, Annu. Rev. Anal. Chem., 2011, 4, 105-128.

230 Y. Lin, Z. Yang, R. J. Lake, C. Zheng and Y. Lu, Angew. Chem., Int. Ed., 2019, 58, 17061-17067.

231 S. H. Mei, Z. Liu, J. D. Brennan and Y. Li, J. Am. Chem. Soc., 2003, 125, 412-420.

232 R. P. Cruz, J. B. Withers and Y. Li, Chem. Biol., 2004, 11, 57-67.

233 K. Schlosser, J. Gu, L. Sule and Y. Li, Nucleic Acids Res., 2008, 36, 1472-1481.

234 S. F. Torabi, P. Wu, C. E. McGhee, L. Chen, K. Hwang, N. Zheng, J. Cheng and Y. Lu, Proc. Natl. Acad. Sci. U. S. A., 2015, 112, 5903-5908.

235 S. W. Santoro and G. F. Joyce, Proc. Natl. Acad. Sci. U. S. A., 1997, 94, 4262-4266.

236 K. Schlosser and Y. Li, ChemBioChem, 2010, 11, 866-879.

237 H. Liu, X. Yu, Y. Chen, J. Zhang, B. Wu, L. Zheng, P. Haruehanroengra, R. Wang, S. Li, J. Lin, J. Li, J. Sheng, Z. Huang, J. Ma and J. Gan, Nat. Commun., 2017, 8, 2006.

238 M. Cepeda-Plaza, C. E. McGhee and Y. Lu, Biochemistry, 2018, 57, 1517-1522.

239 A. K. Brown, J. Li, C. M. Pavot and Y. Lu, Biochemistry, 2003, 42, 7152-7161.

240 M. V. Sednev, V. Mykhailiuk, P. Choudhury, J. Halang, K. E. Sloan, M. T. Bohnsack and C. Höbartner, Angew. Chem., Int. Ed., 2018, 57, 15117-15121.

241 A. Ganguly, B. P. Weissman, J. A. Piccirilli and D. M. York, ACS Catal., 2019, 9, 10612-10617.

242 S. Ekesan and D. M. York, Nucleic Acids Res., 2019, 47, 10282-10295.

243 H. K. Kim, J. Liu, J. Li, N. Nagraj, M. Li, C. M. Pavot and Y. Lu, J. Am. Chem. Soc., 2007, 129, 6896-6902.

244 H. K. Kim, I. Rasnik, J. Liu, T. Ha and Y. Lu, Nat. Chem. Biol., 2007, 3, 763-768.

245 L. Ma, S. Kartik, B. Liu and J. Liu, Nucleic Acids Res., 2019, 47, 8154-8162.

246 M. Buchhaupt, C. Peifer and K.-D. Entian, Anal. Biochem., 2007, 361, 102-108.

247 M. Hengesbach, M. Meusburger, F. Lyko and M. Helm, $R N A, 2008,14,180-187$.

248 D. Graber, H. Moroder, J. Steger, K. Trappl, N. Polacek and R. Micura, Nucleic Acids Res., 2010, 38, 6796-6802.

249 M. Bujnowska, J. Zhang, Q. Dai, E. M. Heideman and J. Fei, J. Biol. Chem., 2020, 295, 6992-7000.
250 D. P. Patil, B. F. Pickering and S. R. Jaffrey, Trends Cell Biol., 2018, 28, 113-127.

251 B. Liu, D. K. Merriman, S. H. Choi, M. A. Schumacher, R. Plangger, C. Kreutz, S. M. Horner, K. D. Meyer and H. M. Al-Hashimi, Nat. Commun., 2018, 9, 2761.

252 N. Liu, Q. Dai, G. Zheng, C. He, M. Parisien and T. Pan, Nature, 2015, 518, 560-564.

253 C. Roost, S. R. Lynch, P. J. Batista, K. Qu, H. Y. Chang and E. T. Kool, J. Am. Chem. Soc., 2015, 137, 2107-2115.

254 R. Micura, W. Pils, C. Höbartner, K. Grubmayr, M. O. Ebert and B. Jaun, Nucleic Acids Res., 2001, 29, 3997-4005.

255 H. Shi, B. Liu, F. Nussbaumer, A. Rangadurai, C. Kreutz and H. M. Al-Hashimi, J. Am. Chem. Soc., 2019, 141, 19988-19993.

256 A. Liaqat, C. Stiller, M. Michel, M. V. Sednev and C. Höbartner, Angew. Chem., Int. Ed., 2020, DOI: 10.1002/anie.202006218.

257 U. Schweizer, S. Bohleber and N. Fradejas-Villar, RNA Biol., 2017, 14, 1197-1208.

258 T. Janas, T. Janas and M. Yarus, RNA, 2012, 18, 2260-2268.

259 J. C. Lam, J. B. Withers and Y. Li, J. Mol. Biol., 2010, 400, 689-701.

260 Y. Yokobayashi, Methods, 2019, 161, 41-45.

261 T. L. Sheppard, P. Ordoukhanian and G. F. Joyce, Proc. Natl. Acad. Sci. U. S. A., 2000, 97, 7802-7807.

262 M. Chandra, A. Sachdeva and S. K. Silverman, Nat. Chem. Biol., 2009, 5, 718-720.

263 Y. Xiao, E. C. Allen and S. K. Silverman, Chem. Commun., 2011, 47, 1749-1751.

264 V. Dokukin and S. K. Silverman, Chem. Sci., 2012, 3, 1707-1714.

265 H. Gu, K. Furukawa, Z. Weinberg, D. F. Berenson and R. R. Breaker, J. Am. Chem. Soc., 2013, 135, 9121-9129.

266 V. Dhamodharan, S. Kobori and Y. Yokobayashi, ACS Chem. Biol., 2017, 12, 2940-2945.

267 F. Praetorius, B. Kick, K. L. Behler, M. N. Honemann, D. Weuster-Botz and H. Dietz, Nature, 2017, 552, 84-87.

268 R. Welz, K. Bossmann, C. Klug, C. Schmidt, H. J. Fritz and S. Müller, Angew. Chem., Int. Ed., 2003, 42, 2424-2427.

269 T. Walton, S. DasGupta, D. Duzdevich, S. S. Oh and J. W. Szostak, Proc. Natl. Acad. Sci. U. S. A., 2020, 117, 5741-5748.

270 F. Wachowius and P. Holliger, ChemSystemsChem, 2019, 1, 1-4.

271 Y. Fujita, H. Furuta and Y. Ikawa, $R N A$, 2009, 15, 877-888. 272 F. Wachowius, J. Attwater and P. Holliger, Q. Rev. Biophys., 2017, 50, e4.

273 D. M. Shechner and D. P. Bartel, Nat. Struct. Mol. Biol., 2011, 18, 1036-1042.

274 D. M. Shechner, R. A. Grant, S. C. Bagby, Y. Koldobskaya, J. A. Piccirilli and D. P. Bartel, Science, 2009, 326, 1271-1275.

275 M. P. Robertson and W. G. Scott, Science, 2007, 315, 1549-1553.

276 D. P. Bartel and J. W. Szostak, Science, 1993, 261, 1411-1418.

277 M. P. Robertson and A. D. Ellington, Nat. Biotechnol., 1999, 17, 62-66. 
278 J. Rogers and G. F. Joyce, RNA, 2001, 7, 395-404.

279 M. P. Robertson and G. F. Joyce, Chem. Biol., 2014, 21, 238-245.

280 Y. Nomura and Y. Yokobayashi, Nucleic Acids Res., 2019, 47, 8950-8960.

281 J. Attwater, A. Wochner and P. Holliger, Nat. Chem., 2013, 5, 1011-1018.

282 J. T. Sczepanski and G. F. Joyce, Nature, 2014, 515, 440-442.

283 J. Attwater, A. Raguram, A. S. Morgunov, E. Gianni and P. Holliger, eLife, 2018, 7, e35255.

284 B. Samanta and G. F. Joyce, eLife, 2017, 6, e31153.

285 K. F. Tjhung, M. N. Shokhirev, D. P. Horning and G. F. Joyce, Proc. Natl. Acad. Sci. U. S. A., 2020, 117, 2906-2913.

286 W. E. Purtha, R. L. Coppins, M. K. Smalley and S. K. Silverman, J. Am. Chem. Soc., 2005, 127, 13124-13125.

287 A. Ponce-Salvatierra, K. Wawrzyniak-Turek, U. Steuerwald, C. Höbartner and V. Pena, Nature, 2016, 529, 231-234.

288 F. Wachowius, F. Javadi-Zarnaghi and C. Höbartner, Angew. Chem., Int. Ed., 2010, 49, 8504-8508.

289 F. Wachowius and C. Höbartner, J. Am. Chem. Soc., 2011, 133, 14888-14891.

290 L. Büttner, J. Seikowski, K. Wawrzyniak, A. Ochmann and C. Höbartner, Bioorg. Med. Chem., 2013, 21, 6171-6180.

291 J. Aranda, M. Terrazas, H. Gomez, N. Villegas and M. Orozco, Nat. Catal., 2019, 2, 544-552.

292 E. J. Mattioli, A. Bottoni and M. Calvaresi, J. Chem. Inf. Model., 2019, 59, 1547-1553.

293 E. Zelin, Y. Wang and S. K. Silverman, Biochemistry, 2006, 45, 2767-2771.

294 R. L. Coppins and S. K. Silverman, Nat. Struct. Mol. Biol., 2004, 11, 270-274.

295 Y. Wang and S. K. Silverman, J. Am. Chem. Soc., 2003, 125, 6880-6881.
296 Y. Wang and S. K. Silverman, Angew. Chem., Int. Ed., 2005, 44, 5863-5866.

297 F. Javadi-Zarnaghi and C. Höbartner, Chem. - Eur. J., 2016, 22, 3720-3728.

298 E. Zelin and S. K. Silverman, ChemBioChem, 2007, 8, 1907-1911.

299 E. Zelin and S. K. Silverman, Chem. Commun., 2009, 767-769.

300 D. A. Baum and S. K. Silverman, Angew. Chem., Int. Ed., 2007, 46, 3502-3504.

301 C. Höbartner and S. K. Silverman, Angew. Chem., Int. Ed., 2007, 46, 7420-7424.

302 F. Javadi-Zarnaghi and C. Höbartner, J. Am. Chem. Soc., 2013, 135, 12839-12848.

303 L. Büttner, F. Javadi-Zarnaghi and C. Höbartner, J. Am. Chem. Soc., 2014, 136, 8131-8137.

304 M. Ghaem Maghami, S. Dey, A. K. Lenz and C. Höbartner, Angew. Chem., Int. Ed., 2020, 59, 9335-9339.

305 M. Ghaem Maghami, C. P. M. Scheitl and C. Höbartner, J. Am. Chem. Soc., 2019, 141, 19546-19549.

306 M. A. Juen, C. H. Wunderlich, F. Nussbaumer, M. Tollinger, G. Kontaxis, R. Konrat, D. F. Hansen and C. Kreutz, Angew. Chem., Int. Ed., 2016, 55, 12008-12012.

307 E. Strebitzer, A. Rangadurai, R. Plangger, J. Kremser, M. A. Juen, M. Tollinger, H. M. Al-Hashimi and C. Kreutz, Chemistry, 2018, 24, 18903-18906.

308 B. Chen, A. P. Longhini, F. Nussbaumer, C. Kreutz, J. D. Dinman and T. K. Dayie, Chem. - Eur. J., 2018, 24, 5462-5468.

309 Y. Xue, B. Gracia, D. Herschlag, R. Russell and H. M. Al-Hashimi, Nat. Commun., 2016, 7, ncomms11768.

310 I. J. Kimsey, K. Petzold, B. Sathyamoorthy, Z. W. Stein and H. M. Al-Hashimi, Nature, 2015, 519, 315-320. 